\title{
Influence of Contextual Factors on Soundscape in Urban Open Spaces
}

\author{
Xiaolong Zhao ${ }^{1}$, Shilun Zhang ${ }^{1}{ }^{(}$, Qi Meng ${ }^{1, *}$ and Jian Kang $\left.{ }^{1,2}{ }^{(}\right)$ \\ 1 Key Laboratory of Cold Region Urban and Rural Human Settlement Environment Science and Technology, \\ Ministry of Industry and Information Technology, School of Architecture, Harbin Institute of Technology, \\ Harbin 150001, China. zhaoxiaolong@hit.edu.cn (X.Z.); shil.zhang@outlook.com (S.Z.); \\ j.kang@ucl.ac.uk (J.K.) \\ 2 UCL Institute for Environmental Design and Engineering, University College London (UCL), \\ London WC1H 0NN, UK \\ * Correspondence: mengq@hit.edu.cn; Tel.: +86-151-0451-5125
}

Received: 13 November 2018; Accepted: 4 December 2018; Published: 6 December 2018

check for updates

Featured Application: This study is expected to be applied in the improvement of soundscape quality in urban open spaces, especially in commercial pedestrian streets.

\begin{abstract}
The acoustic environment in urban open spaces has played a key role for users. This study analyzed the different effects of contextual factors, including shop openness, season, and commercial function, on the soundscape in two typical commercial pedestrian streets. The following observations were based on a series of measurements, including crowd measurements, acoustic environment measurements, and a questionnaire survey. First, the number of talkers in Central Avenue was greater than the number of talkers in Kuan Alley in cases with the same crowd density, while there was no significant difference in the sound pressure level. When the crowd density increased, acoustic comfort trended downward in Kuan Alley, while the value of acoustic comfort in Central Avenue took a parabolic shape. Second, there was no significant difference between the number of talkers in summer and the number of talkers in winter; however, when crowd density increased by 0.1 persons $/ \mathrm{m}^{2}$, the level of sound pressure increased by $1.3 \mathrm{dBA}$ in winter and $2.2 \mathrm{dBA}$ in summer. Acoustic comfort took a parabolic shape that first increased and then decreased in both winter and summer. Regarding commercial function, as the crowd density increased, the number of talkers and the level of sound pressure both increased, while acoustic comfort decreased in three zones with different commercial functions. In addition, a cross-tab analysis was used to discuss the relationship between the number of talkers and the level of sound pressure, and it was found to be positive.
\end{abstract}

Keywords: urban open spaces; contextual factors; soundscape

\section{Introduction}

The context of urban open spaces, especially the acoustic environment, has played an indispensable role in the experience of users of those spaces since residents and tourists pay more attention to acoustic perception than visual satisfaction [1]. With the spread of urbanization, urban open spaces will be increasingly multifunctional and integrated, and crowds will be exposed to noise because of complex acoustic contexts [2,3]. Many previous studies focused on how to prevent and control noise, using tools such as predictive models, noise maps and noise barriers [4-8], while the quality of the sound environment had not been improved effectively. Currently, there is a tendency to shift the focus from purely noise control to overall soundscape design, which brings a change to the field of sound environment design. Soundscape, an important aspect of evaluating an acoustic environment, has been 
widely applied to studies of acoustic environments in urban open spaces [9-12]. Different from noise control engineering, the soundscape is the acoustic environment as perceived or experienced and/or understood by a person or people, as defined by the ISO. It represents a timely paradigm shift in that it considers environmental sounds like a 'resource' rather than a 'waste' [13].

Acoustic factors such as sound sources, absorption coefficient, sound pressure level and reverberation time are of primary importance in a wide range of studies [13-16]. Regarding sound sources, some studies prefer to discuss the types, the masking effects, and the perception of sound sources as a general rule. Yu and Kang considered that the sound sources mainly included 4 types: natural, human, mechanical, and instrumental sounds based on 19 urban squares [17]. Among these types of sound sources, natural sounds and traffic noise have been increasingly considered in recent years, especially their effects on perceptions from citizens [2,18-20]. Several works still attempted to explore the effect of using natural and artificial sounds to reduce the impact of traffic noise [14,21,22]. Additionally, other studies aimed to improve the acoustic environment by using vegetation to absorb sound in urban open spaces. Lai and Ghosh carried out a study to determine the effect of roadside vegetation on the reduction of road traffic noise under varying planting intensities [23]. Traditionally, sound pressure level and reverberation time were frequently used as acoustic factors to estimate a given acoustic context in urban open spaces [10,24-26]. Kang noted that the reverberation time and the early decay time are significantly longer and the sound pressure level attenuation with distance is generally smaller in urban squares unless the height/side ratio is high compared to diffuse boundaries with geometrical boundaries [24].

Soundscape studies have contained both acoustic and contextual factors affecting human perception of the acoustic environment. Now, contextual factors such as spatial, temporal, and functional factors are receiving great attention $[10,22,27,28]$. A number of studies have noted that spatial locations and regions can change the diversity of sound sources, acoustic environments and sequentially affect citizens' evaluation of acoustic quality $[4,8,29]$. Temporal factors could refer to the time of a day or the seasons of a year. Kang, Song et al. proposed that subjective and objective evaluations of acoustic environments were different in different seasons [18,30]. Some related studies explored the seasonal effect of the temperature difference on soundscape [31-35]. In terms of functional factors, many previous studies indicated that soundscape assessments were influenced by the functions of places, including commercial, residential, business, and recreational places. [12,29,36]. Hong and Jin pointed out that places with different functions might be evaluated differently, even if the same sound sources existed in a place [29]. In particular, a crowd is considered a special type of sound source. While a crowd may be a source of noise, a crowd also has a sound-absorption effect. In some typical urban open spaces, crowd density, to some extent, can affect speed articulation, reverberation time, and acoustic comfort [22,28]. Certain works proposed that crowd density and the level of sound pressure in urban open spaces were strongly relevant $[22,28]$. Thus, the influence of crowd density was also taken into account in this study.

As we discussed above, contextual factors have played key roles in soundscape studies. However, these factors were not studied in a systematic way, and there were also many gaps in related studies. The spatial factor was generally investigated in many cross-cultural soundscape research studies, but it has still not been compared in southern and northern China. On the other hand, the openness of shops (to be explained in detail in Section 2.1 in this paper) was significantly different in commercial pedestrian streets in southern and northern China, which may influence soundscape to a different extent. In addition, the temperature difference between winter and summer was relatively high in many cities of northern China, where the highest temperatures could reach 50-60 ${ }^{\circ} \mathrm{C}$ [37]. This factor in northern China had also never been considered in related studies. In addition, a pedestrian street in China generally includes certain commercial establishments, such as restaurants, stores, recreational spaces, and so on. The effects of different commercial functions on soundscape in a pedestrian street in southern China were also investigated by few studies. Consequently, the aim of this study was to identify the influence of contextual factors on the soundscape in commercial pedestrian streets in China. 
First, the study assessed the influence of semi-open and closed shop openness on the soundscape in two commercial pedestrian streets. Second, the study investigated the difference in the soundscape in a commercial pedestrian street between summer and winter. Finally, this study examined how commercial function influences the soundscape in a commercial pedestrian street.

Some key terms used in this paper are explained as follows: (1) Crowd density. The acoustic environment and users' acoustic perceptions can be affected by crowd density since a crowd is a special sound source as it gives rise to certain sound absorption effects [22,28]. It is calculated as the total number of signal users divided by the area of survey sites, which gives the average number of persons per square meter [27]. The unit of crowd density is persons $/ \mathrm{m}^{2}$. (2) Conversation behavior. In this study, this factor was quantified as the number of talkers, specifically the average number of people who talked for more than two seconds. (3) Sound pressure level. This value is a logarithmic measure of the effective pressure of a sound relative to a reference value. The unit of sound pressure level is $\mathrm{dB}[38,39]$. (4) Acoustic comfort. This measurement is the subjective evaluation of a user in the sound environment according to a five-point scale in this study: 1 , very uncomfortable; 2 , uncomfortable; 3 , neither comfortable nor uncomfortable; 4 , comfortable; 5 , very comfortable [40].

\section{Methodology}

\subsection{Survey Sites}

As an important component of urban open spaces, commercial pedestrian streets have developed into public places for consumption, sightseeing, leisure, and recreation. Typical commercial pedestrian streets are usually considered landmarks and the economic and cultural centers of cities. Therefore, this study selected two typical commercial pedestrian streets as survey sites, Kuan Alley and Central Avenue (shown in Table 1) for the following reasons. The first reason is the sites' long history. These two commercial pedestrian streets are 100-300 years old and are important cultural heritage sites in the world. Second, the sites are in the central city. These two commercial pedestrian streets are local landmarks, tourist resorts, and shopping spaces that attract large crowds, which provide a good basis to make the investigation comprehensive. Furthermore, commercial models in these two commercial pedestrian streets are similar to commercial streets in Europe and Asia. The contextual factors, such as the shop openness and mode of operation, were significantly different in typical commercial pedestrian streets within many districts in northern and southern China as a result of the differences in climate, traditional culture, and economic level. The shop openness means the open degree of the envelope of the shops. For instance, the shop openness in Kuan Alley was generally in a semi-open mode, namely, doors and windows were usually open during the business period. In contrast, the shop openness was in a closed mode in Central Avenue, namely, the doors and windows in this commercial pedestrian street were usually closed, especially in winter.

In an urban environment, there are often different functional zones. In each zone, there may be a dominant sound [20]. These dominant sound sources differ because of the different commercial functions in a commercial pedestrian street. Considering the influence of different dominant sound sources on the soundscape [25], a commercial pedestrian street is divided into three commercial functional zones: the Di (dining) zone, the Sp (shopping) zone, and the Pe (performance) zone (shown in Figure 1). In the Di zone, hawking was a dominant sound source users usually paid more attention to (shown in Figure 2). In the Sp zone, background music is played by the PA system for customers to increase the economic benefit ratio. In the Pe zone, live instrumental music is played for customers by folk artists with instruments. The speech that is a general sound source among all the zones should also be considered. However, other sounds, such as taking footsteps, can be neglected because they do not significantly affect the soundscape [41]. To avoid the interference of traffic noise from the motorway and sound sources in other zones, the distance between the survey zone and the motorway and between the two survey zones was at least $20 \mathrm{~m}$ [22]. The length of each survey zone was set at 
$30 \mathrm{~m}$. In order to avoid the influence of commercial functions, the difference of shop openness in Sp zone in two pedestrian streets was compared as an example.

Table 1. The fundamental state of the survey sites.

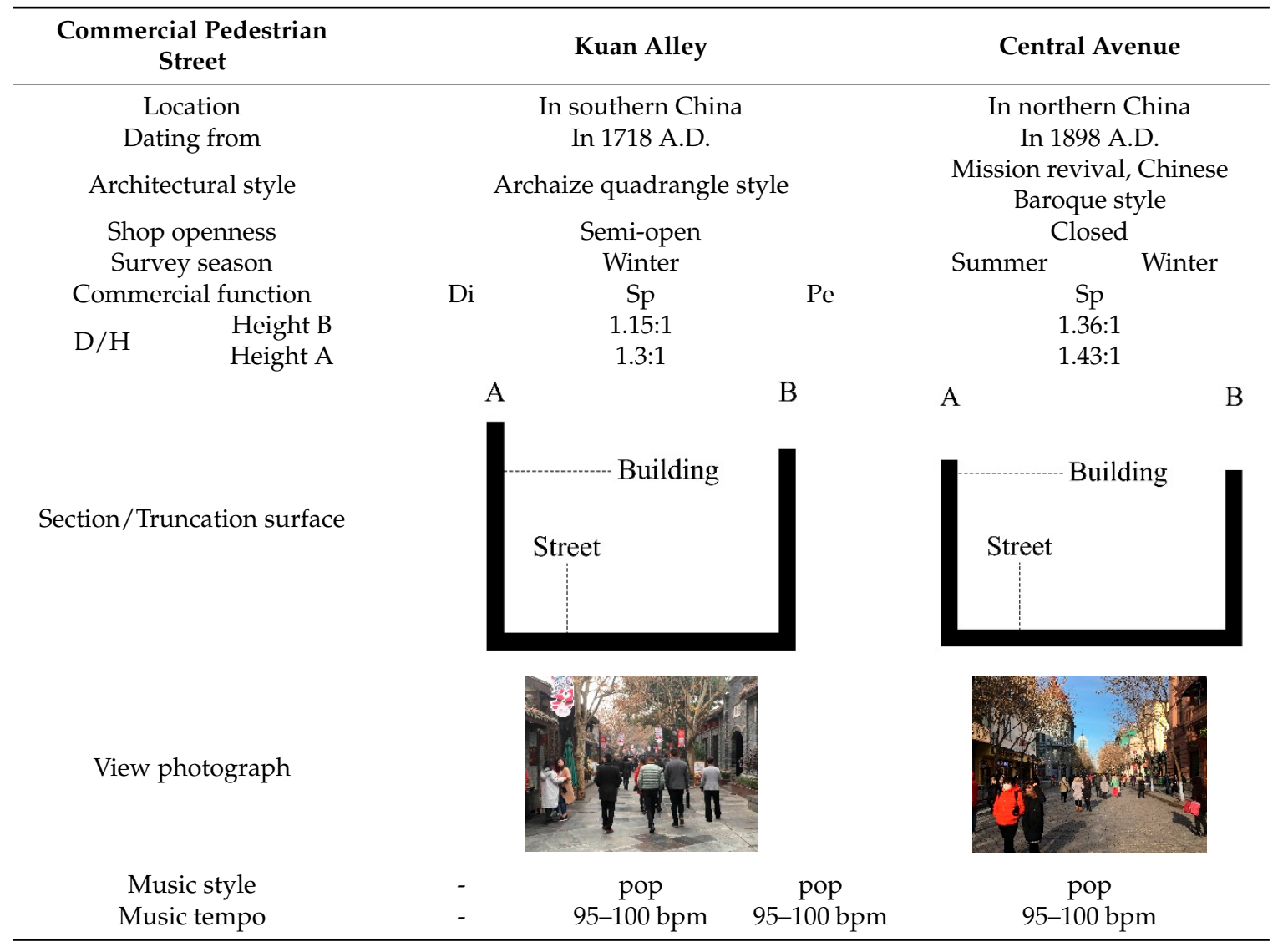

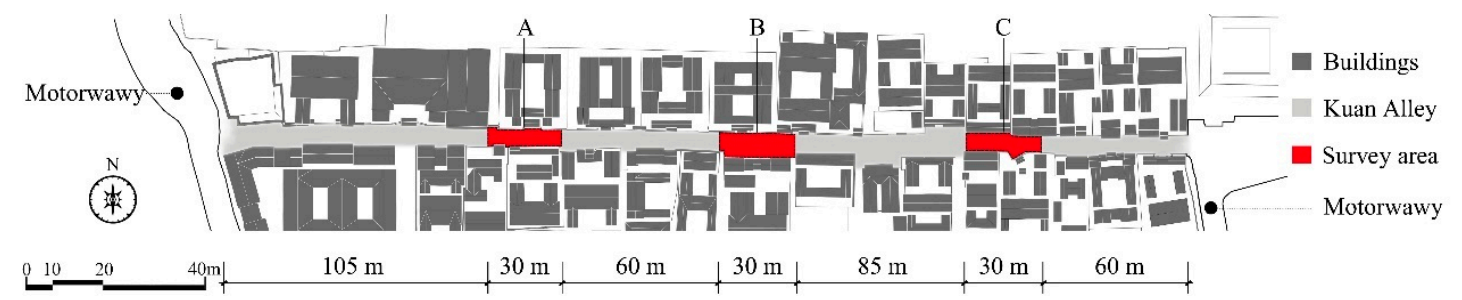

(a)

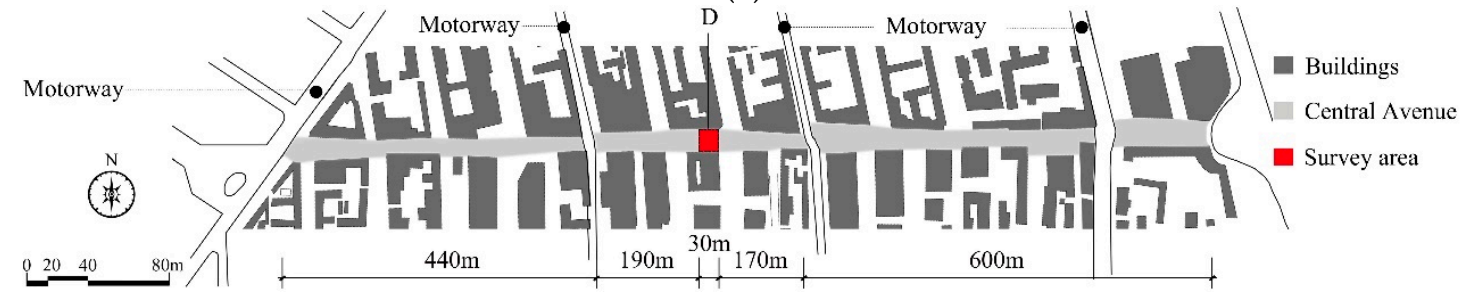

(b)

Figure 1. The survey areas of commercial pedestrian streets: (a) Kuan Alley; (b) Central Avenue, and A refers to the Di zone, B and D refer to the Sp zone, C refers to the Pe zone. 


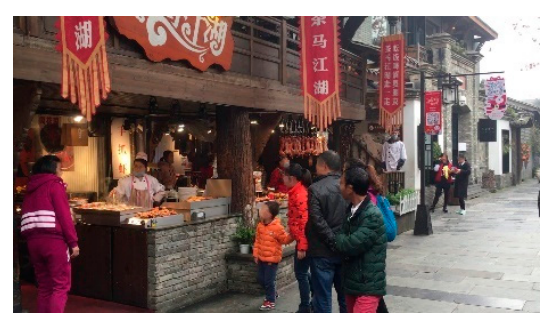

(a)

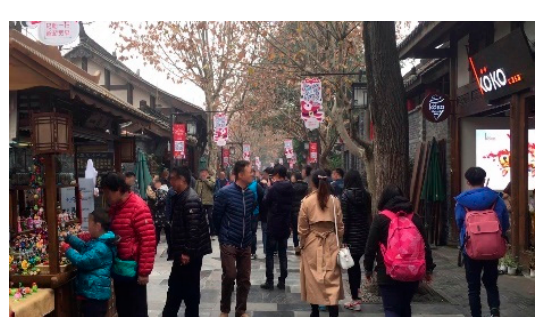

(b)

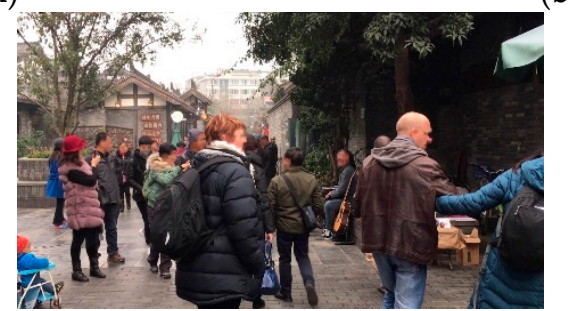

(c)

Figure 2. Photos of the Di zone (a), the Sp zone (b) and the Pe zone (c) in Kuan Alley.

\subsection{Survey Planning}

The survey was carried out in two seasons [12]: winter and summer. In Central Avenue, 18 days were chosen as the survey days from 1 June 2017 to 30 July 2017 and from 1 December 2016 to 30 January 2017. These days were chosen because they are typical, with the daily mean temperature from 14 to $25^{\circ} \mathrm{C}$ in summer and from -18 to $-7^{\circ} \mathrm{C}$ in winter. In Kuan Alley, 8 days were chosen as the typical survey days from 1 December 2016 to 30 January 2017, with the daily mean temperature ranging from 6 to $12{ }^{\circ} \mathrm{C}$ in winter. A total of 26 days were required to perform the soundscape measurements during clear weather. In these days, both weekdays and weekends were considered for data collection to make crowd density samples more sufficient. In addition, there were no significant differences with regard to demographic composition and distribution between weekdays and weekends in the two pedestrian streets in a preliminary study $[10,42]$. On each survey day, data on crowd characteristics, sound pressure level, acoustic comfort, and individual characteristics were collected by 10 volunteers from 8:00 am to 6:00 pm on weekdays and weekends. The crowd measurement contained two parts: the crowd density measurement and the number of talkers. Most importantly, in crowd measurement, each participant's facial features were recorded as mosaics, and the participant's vehicle information recorded on video was also processed in order to protect confidentiality [43,44]. In the questionnaire part, participants volunteered to participate in the questionnaire survey. Their private information would not be recorded for the same reason [42].

\subsection{Crowd Density Measurement}

To study the effect of a crowd on the acoustic environment and acoustic perception in commercial pedestrian streets, crowd density was measured using a photographic method with a small remote drone (type: DJ inspire 2) [45]. To avoid the interference of leaves and architectural shadows on the results, the shooting angle was set to $65^{\circ}$ vertical to the ground (Figure 3). To avoid the influence of the small drone on the visual and aural perception of users, the distance between the small drone and the ground was set at $10 \mathrm{~m}$. Measurements were taken every 25-30 min between the hours of 8:00 am and 6:00 pm. One photograph was taken every $30 \mathrm{~s}$ continuously for $5 \mathrm{~min}$ [27]. To calculate the statistics of the number of persons, a red dot was used to mark user location within survey zones in the photos (shown in Figure 3) to reduce measurement error. The total number of red dots in 5 min was divided by the number of photos and then divided by the measurement area to obtain a mean value of crowd density; the unit was persons $/ \mathrm{m}^{2}[22,27,28]$. 

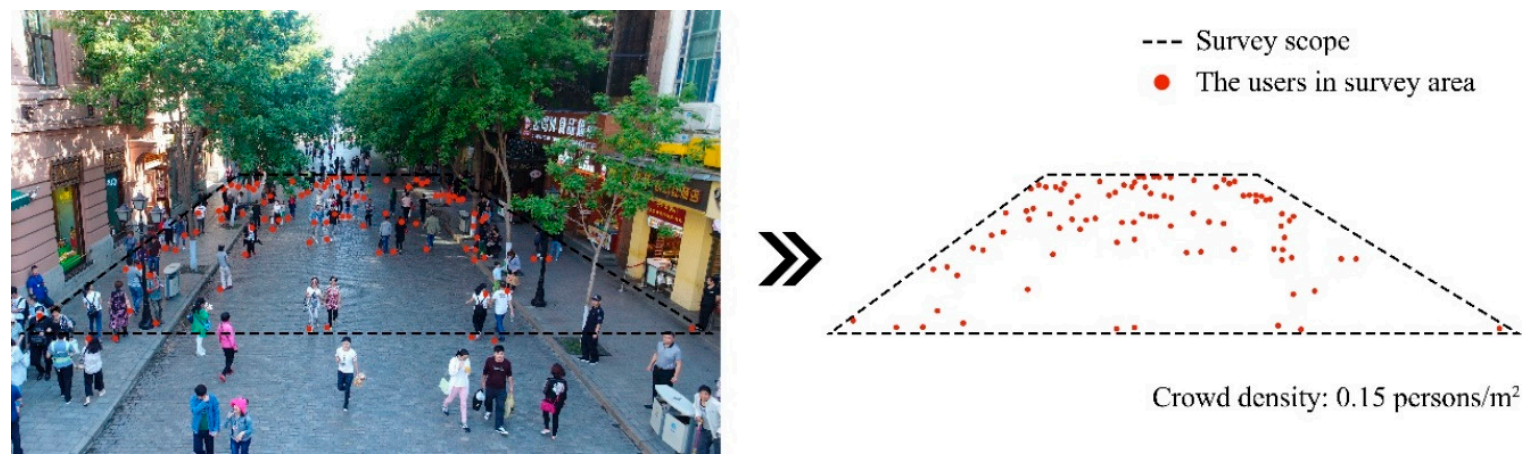

Crowd density: 0.15 persons $/ \mathrm{m}^{2}$

Figure 3. The crowd density measurement.

\subsection{Conversation Behavior Measurement}

Previous studies have suggested that the sounds produced by humans in conversation are of primary importance to soundscapes [46]. Thus, the study of the effect of conversation behavior on the sound environment is also very important. In previous behavioral research, the methods of investigation were classified as self-report measures and naturalistic observations $[47,48]$. In effect, the evidence showed that self-reports failed to provide an objective account of observed behavior, instead producing data reflective of respondents' subjective interpretations of reality [49]. Generally, self-reports were impacted by reporting errors, such as response bias, acquiescent responding [50], and socially desirable responding [50,51]. Compared to self-reports, naturalistic observations hold the benefit of providing a direct measurement of behaviors and have been demonstrated to be a reliable representation of crowd behavior [52]. Therefore, it was utilized in this paper to measure the conversation behavior of the crowd. To quantify the conversation behavior, the number of talkers was recorded as an indicator of conversation behavior by an HDV (high definition video camera, type: DJ OSMO+). The observations were made under completely natural conditions since the subjects generally did not know that they were being observed. Thus, their behaviors were genuine and the data from observations were reliable. Considering that the visual angle of an HDV is $94^{\circ}$ and the focal length is $22-77 \mathrm{~mm}$, each survey zone was divided into three equal sections. There were HDVs in two corners of each section, to avoid blind areas such as the red section shown in Figure 4. To reduce measurement error, the recording of the HDV and the measurement of the small drone were taken at the same time continuously for $5 \mathrm{~min}$ [11]. The video collection was also carried out every 25-30 min between the hours of 8:00 am and 6:00 pm. The number of videos was approximately 18-21 groups in each survey zone to capture the entire distribution of measurement [11]. The laboratory used an approach of replaying video to count the number of talkers. It usually took an average of $30 \mathrm{~s}$ to walk from section A to B (shown in Figure 4), so the number of talkers was computed every $30 \mathrm{~s}$ to avoid the impact of changes in crowd traffic. Then, the average number of talkers per $5 \mathrm{~min}$ in each survey zone was calculated. In the statistical considerations of the number of talkers, subjects with a duration of conversation less than $2 \mathrm{~s}$ were eliminated because short-duration behavior $(<2 \mathrm{~s})$ would make a negligible impact on the sound environment $[53,54]$. 


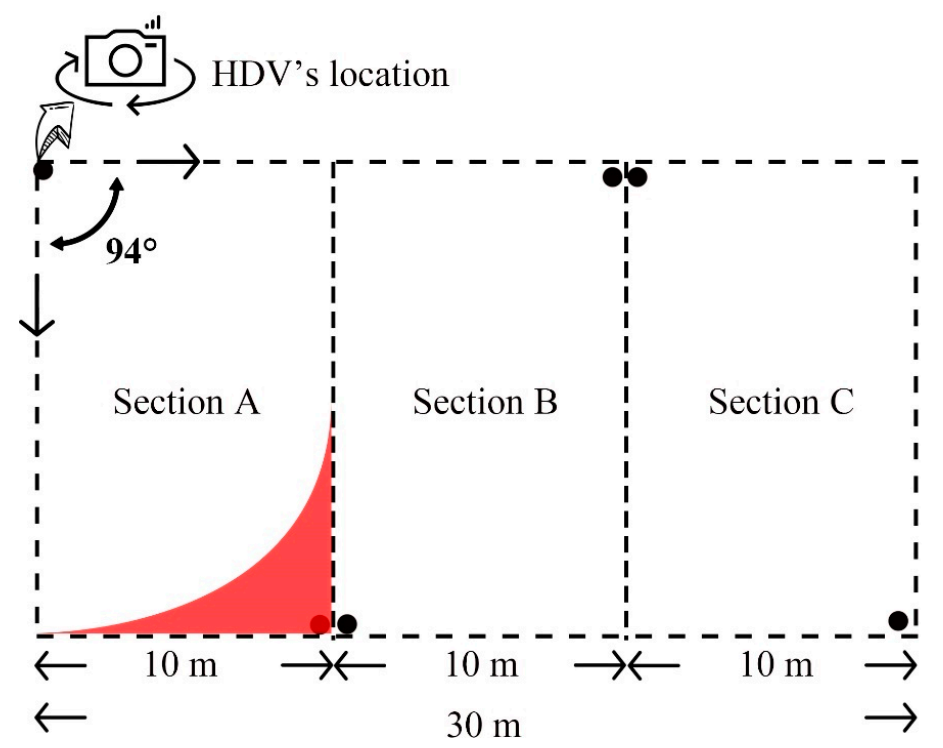

Figure 4. The conversation behavior in each section of the survey zone.

\subsection{Acoustic Environment Measurement}

Previous studies have suggested that different aggregate crowd states and behavior patterns influence the sound environment and acoustic perception of users in open spaces [55-57]. Therefore, in field acoustic measurements, the level of sound pressure in every survey zone was measured with the following methods to study the characteristics of sound emission from a crowd. The sound pressure level was recorded immediately after each measurement of crowd density and conversation behavior. The sound pressure level meter was set to the slow-mode and A-weight, and a reading for instantaneous data was taken every $10 \mathrm{~s}$. The probe of the sound level meter was positioned $1 \mathrm{~m}$ away from walls and other main reflectors and 1.2-1.5 $\mathrm{m}$ off the ground [58]. A total of $5 \mathrm{~min}$ of data [59] were obtained at each measurement position, and the corresponding A-weight equivalent sound pressure level was derived. To reduce measurement errors, each measurement in each survey zone was taken from at least five random points $\left(R_{1}-R_{5}\right.$ are shown in Figure 5), with a distance of at least $5 \mathrm{~m}$ [16]. To avoid the interference of speech in the measurement, there were no persons talking within $3 \mathrm{~m}$ of the scope [22]. The A-weight sound pressure levels measured at each point were then averaged [27].

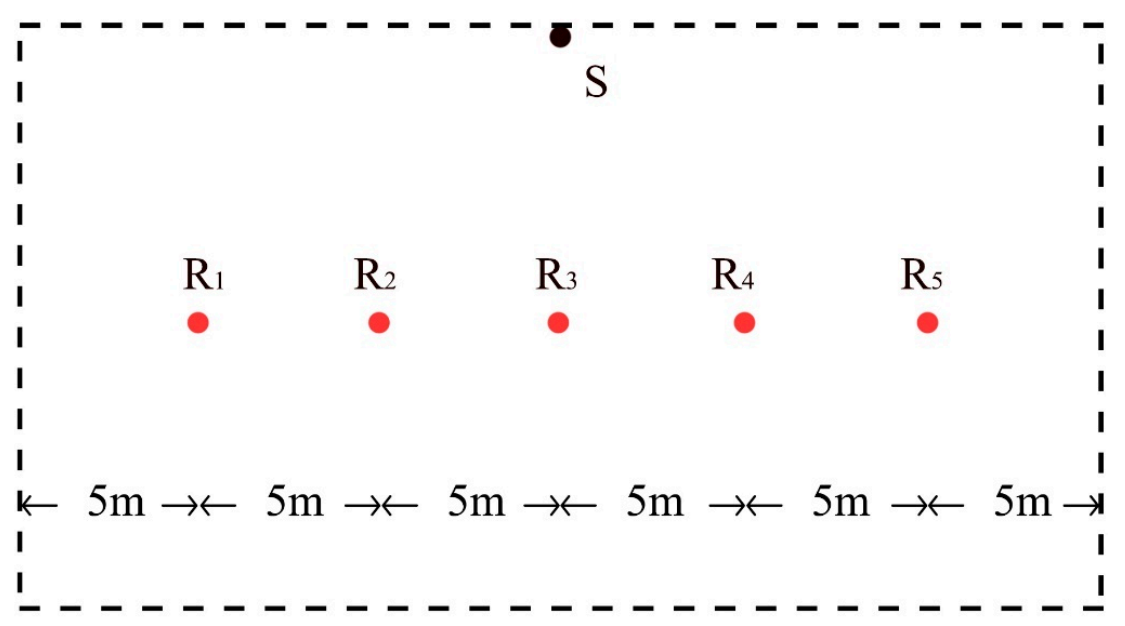

Figure 5. The acoustic environment measurement in the survey zone: $\mathrm{S}$ means sound source and $\mathrm{R}$ means receptions. 


\subsection{Questionnaire Survey}

Acoustic comfort is a common evaluation index for the sound environment in urban open spaces. It describes the subjective psychological perception of sound by the human ear [60] and has been recognized by ISO [61]. Although there is currently much debate in progress about the best methods to gather information on sound perception by the public, a questionnaire survey is still a frequently used approach to investigate acoustic comfort $[3,15,62,63]$. In addition, before the formal investigation, the reliability and validity of the questionnaire were tested. The values of Cronbach's Alpha and KMO were 0.86 and 0.81 , respectively, which meant our questionnaire is reliable $[64,65]$. Thus, in this study, a questionnaire survey was carried out to study the effects of contextual factors on acoustic comfort. The questions covered users' social characteristics and acoustic comfort [66]. On acoustic comfort, interviewees answered using the following five-point Likert-type scale: 1 , very uncomfortable; 2 , uncomfortable; 3 , neither comfortable nor uncomfortable; 4 , comfortable; 5, very comfortable. After the measurement of crowd density, conversation behavior, and sound environment, selected users were immediately extracted and invited to take a questionnaire survey. The questionnaire was anonymous and the form of the questionnaire distribution was random. The interviewers were instructed to explain the questions and ensure that interviewees understood them. Previous studies have also indicated that an interview of more than 5 min may decrease the reliability of the investigation $[27,67]$, so the questionnaires in this study were all delivered and finished within 2-3 min. A total of 5153 individuals aged from 18-55 years were invited to participate from two pedestrian streets in China (Table 2). Approximately $40 \%$ of the respondents were male, and $60 \%$ of the respondents were female. The sample was stratified for age according to the following age strata: $18-30,31-45,46-55$ years [68].

Table 2. The fundamentals of the state of the investigation population.

\begin{tabular}{cccc}
\hline & & \multicolumn{2}{c}{ Number/Percentage } \\
\hline \multirow{2}{*}{ Commercial Pedestrian Street } & Kuan Alley & Central Avenue \\
\hline \multirow{2}{*}{ Survey season } & Winter & $3030(100 \%)$ & $1130(53.2 \%)$ \\
& Summer & - & $993(46.8 \%)$ \\
\hline \multirow{3}{*}{ Commercial function } & Di & $966(31.9 \%)$ & - \\
& Sp & $1024(33.8 \%)$ & $2123(100 \%)$ \\
& Pe & $1040(34.3 \%)$ & - \\
\hline \multirow{2}{*}{ Gender } & Male & $1231(40.6 \%)$ & $833(39.2 \%)$ \\
& Female & $1799(59.4 \%)$ & $1290(60.8 \%)$ \\
\hline \multirow{2}{*}{ Identity } & Tourist & $2272(75.0 \%)$ & $1179(55.5 \%)$ \\
& Resident & $758(25.0 \%)$ & $944(44.5 \%)$ \\
\hline \multirow{2}{*}{ Age } & $18-30$ years & $1256(41.5 \%)$ & $952(44.8 \%)$ \\
& $31-45$ years & $1031(34.0 \%)$ & $755(35.6 \%)$ \\
& $46-55$ years & $743(24.5 \%)$ & $416(19.6 \%)$ \\
\hline \multirow{2}{*}{} & & $3030(100 \%)$ & $2123(100 \%)$ \\
\hline
\end{tabular}

\subsection{Data Analysis}

Based on the collections of crowd data and soundscape data, the software SPSS [69] was used to analyze the relationship between crowd density and the soundscape in two typical commercial pedestrian streets. First, the distribution of the samples was analyzed. The values of skewness $(<1)$, kurtosis $(<1)$ and variance for the samples are shown in Table 3. A Kolmogorov-Smirnov Test was used to analyze the normality of the data, indicating that all $\mathrm{p}$ values are more than 0.05 . Therefore, all samples followed the normal distribution [68]. Second, Pearson correlation was used to calculate the relationship between crowd density and the number of talkers, the relationship between crowd density and sound environment (sound pressure level and loudness), and the relationship between 
crowd density and acoustic comfort, whilst considering the difference of shop openness, season and commercial function (Table 4); a $t$-test at $p<0.01$ and $p<0.05$ was used to test for significant differences. Additionally, an analysis of variance (ANOVA) was used to test for significant differences between the two shop openness values, two seasons, and three commercial functional zones. The linear and nonlinear regression analyses were used to establish the regression equations of crowd density and the number of talkers, crowd density and sound environment, and crowd density and acoustic comfort.

Figure 6 shows the relationship between crowd density and the number of talkers, taking the Di zone as an example, along with the corresponding regression curves, the coefficient of determination $R^{2}$, and $p<0.001$. Different regression curves, including linear, quadratic and cubic, were used to determine the best fit to show the relationship between crowd density and the number of talkers, as measured by the value of the coefficient of determination $R^{2}$ and statistically significant differences. The value of $R^{2}$ with quadratic regression in the Di zone is highest; however, the value of $p$ is higher than 0.1. The linear regression for the Di zone is better than the cubic regression, with the value of $R^{2}=0.727$ and with $p<0.001$. Thus, this linear regression is used to explain the relationship between crowd density and the number of talkers.

Table 3. The normality of samples.

\begin{tabular}{ccccccc}
\hline Commercial Pedestrian Street & \multicolumn{2}{c}{ Kuan Alley } & \multicolumn{3}{c}{ Central Avenue } \\
\hline \multicolumn{2}{c}{ Commercial Function } & Di & Sp & Pe & \multicolumn{2}{c}{ Sp } \\
\hline \multicolumn{2}{c}{ Survey Season } & & Winter & & Summer & Winter \\
\hline \multirow{2}{*}{ Crowd density } & Skewness & 0.217 & 0.128 & 0.119 & 0.171 & -0.727 \\
& Kurtosis & -0.764 & -0.535 & -0.129 & -0.782 & 0.276 \\
& Variance & 0.008 & 0.007 & 0.007 & 0.004 & 0.005 \\
\hline \multirow{2}{*}{ The number of } & Skewness & 0.577 & 0.610 & -0.003 & 0.287 & 0.053 \\
talkers & Kurtosis & -0.089 & 0.458 & -0.827 & -0.485 & -0.810 \\
& Variance & 12.924 & 15.662 & 13.170 & 44.252 & 68.872 \\
\hline \multirow{2}{*}{ Sound pressure } & Skewness & 0.069 & -0.058 & 0.301 & 0.274 & -0.744 \\
level & Kurtosis & -0.234 & -0.657 & -0.282 & -0.592 & 0.528 \\
& Variance & 2.438 & 1.586 & 2.165 & 1.443 & 4.547 \\
\hline \multirow{2}{*}{ Acoustic } & Skewness & 0.086 & -0.387 & -0.492 & -0.600 & -0.992 \\
comfort & Kurtosis & -0.417 & -0.919 & -0.683 & -0.395 & 0.877 \\
& Variance & 0.213 & 0.380 & 0.309 & 0.313 & 0.183 \\
\hline
\end{tabular}

Table 4. The relationship between crowd density and the number of talkers, between crowd density and sound pressure level, and between crowd density and acoustic comfort.

\begin{tabular}{|c|c|c|c|c|c|c|}
\hline \multirow{3}{*}{\multicolumn{2}{|c|}{$\begin{array}{c}\text { Commercial Pedestrian Street } \\
\text { Commercial Function } \\
\text { Survey Season }\end{array}$}} & \multicolumn{3}{|c|}{ Kuan Alley } & \multirow{2}{*}{\multicolumn{2}{|c|}{$\begin{array}{c}\text { Central Avenue } \\
\mathrm{Sp}\end{array}$}} \\
\hline & & & \multirow{2}{*}{$\begin{array}{c}\mathrm{Sp} \\
\text { Winter }\end{array}$} & \multirow[t]{2}{*}{$\mathrm{Pe}$} & & \\
\hline & & & & & Summer & Winter \\
\hline \multirow{4}{*}{$R /$ Sig } & $\begin{array}{l}\text { Crowd density } \\
\text { and the number of } \\
\text { talkers }\end{array}$ & $\begin{array}{c}0.853 \\
0.000^{* *}\end{array}$ & $\begin{array}{c}0.720 \\
0.000 * *\end{array}$ & $\begin{array}{c}0.797 \\
0.000 * *\end{array}$ & $\begin{array}{c}0.846 \\
0.000 * *\end{array}$ & $\begin{array}{c}0.848 \\
0.000 * *\end{array}$ \\
\hline & $\begin{array}{l}\text { Crowd density } \\
\text { and sound } \\
\text { pressure level }\end{array}$ & $\begin{array}{c}0.798 \\
0.000^{* *}\end{array}$ & $\begin{array}{c}0.723 \\
0.000 * *\end{array}$ & $\begin{array}{c}0.788 \\
0.000^{* *}\end{array}$ & $\begin{array}{c}0.710 \\
0.000^{* *}\end{array}$ & $\begin{array}{c}0.685 \\
0.000^{* *}\end{array}$ \\
\hline & $\begin{array}{l}\text { Crowd density } \\
\text { and loudness }\end{array}$ & $\begin{array}{c}0.803 \\
0.000^{* *}\end{array}$ & $\begin{array}{c}0.700 \\
0.000^{* *}\end{array}$ & $\begin{array}{c}0.788 \\
0.000^{* *}\end{array}$ & $\begin{array}{c}0.662 \\
0.000 * *\end{array}$ & $\begin{array}{c}0.653 \\
0.000 * *\end{array}$ \\
\hline & $\begin{array}{l}\text { Crowd density } \\
\text { and acoustic } \\
\text { comfort }\end{array}$ & $\begin{array}{l}-0.647 \\
0.000 * *\end{array}$ & $\begin{array}{l}-0.669 \\
0.000 * *\end{array}$ & $\begin{array}{l}-0.659 \\
0.000 * *\end{array}$ & $\begin{array}{c}0.697 \\
0.000 * *\end{array}$ & $\begin{array}{c}0.658 \\
0.000 * *\end{array}$ \\
\hline
\end{tabular}




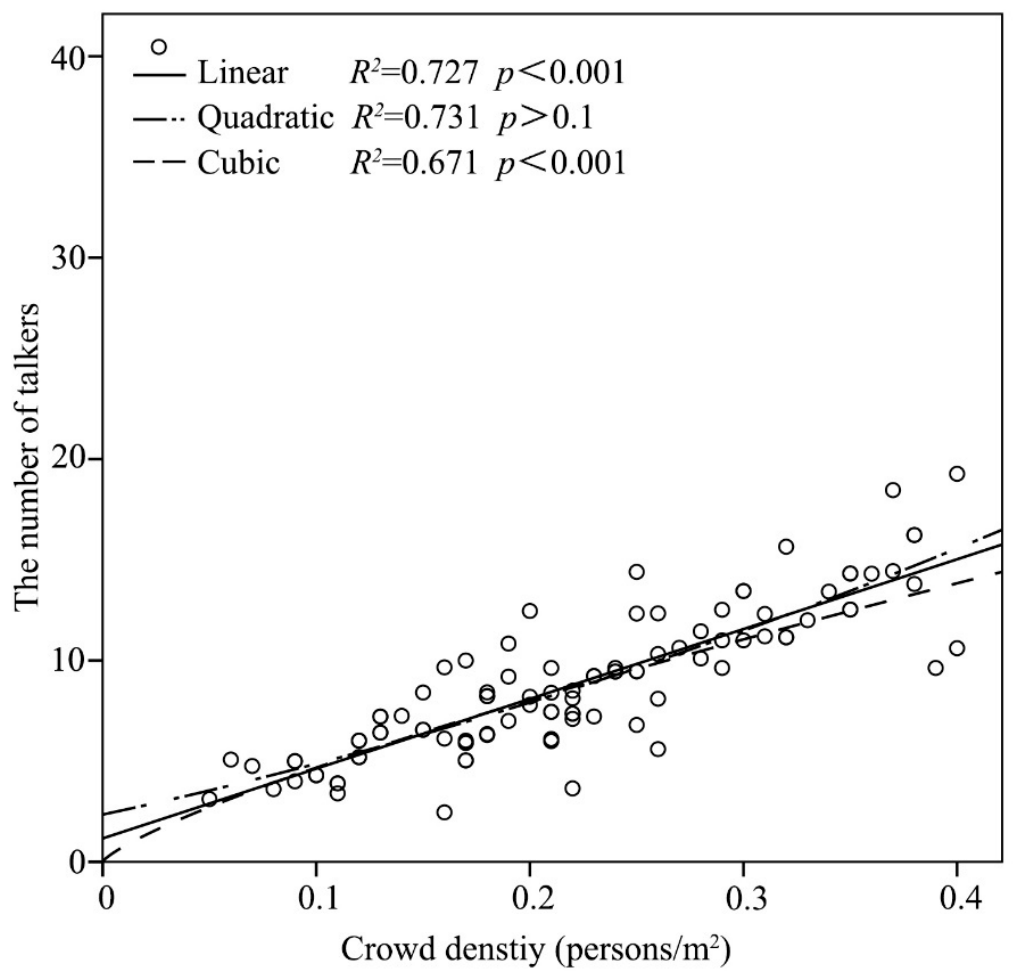

Figure 6. The relationship between crowd density and the number of talkers with three regression curves in the Di zone.

\section{Results}

In this section, the effects of crowd density on soundscape were analyzed, considering cases with different shop openness, season and commercial function.

\subsection{The Influence of Shop Openness}

\subsubsection{The Influence on the Number of Talkers}

Figure 7a shows the relationship between crowd density and the number of talkers: when crowd density increased, the number of talkers increased in both Kuan Alley and Central Avenue, with $R^{2}=0.519$ in Kuan Alley and 0.716 in Central Avenue $(p<0.001)$. The number of talkers in Central Avenue was more than the number of talkers in Kuan Alley when the crowd density was the same. For instance, when the crowd density was 0.1 persons $/ \mathrm{m}^{2}$, the number of talkers in Central Avenue was 6.5 more talkers than in Kuan Alley, and when the crowd density was 0.3 persons $/ \mathrm{m}^{2}$, the number of talkers in Central Avenue was 19.7 more talkers than in Kuan Alley. One possible reason may be that the spatial capability of Central Avenue was larger than that in Kuan Alley.

\subsubsection{The Influence on the Sound Environment}

Figure $7 \mathrm{~b}$ shows the relationship between crowd density and A-weight sound pressure level: when crowd density increased, the level of sound pressure also increased in Kuan Alley and Central Avenue, with $R^{2}=0.527$ in Kuan Alley and 0.470 in Central Avenue $(p<0.001)$. It is interesting to note that the number of talkers in Central Avenue was higher than the number of talkers in Kuan Alley, in which the crowd density was the same; however, there was little difference between the sound pressure levels in Kuan Alley and Central Avenue. One possible reason may be that the voices of users in Kuan Alley were higher than the voices of users in Central Avenue when the crowd density remained the same. 
To study the influence of crowd density on a typical psychoacoustic parameter, loudness, the relationship between crowd density and loudness was calculated. The loudness was calculated using Artemis [70]. It is revealed that crowd density is significantly correlated with loudness $(p<0.001)$, as shown in Table 4. Figure 7c shows the relationship between crowd density and loudness. It can be seen that when crowd density increased, loudness also increases in both Kuan Alley and Central Avenue, with $R^{2}=0.490$ and $0.427(p<0.001)$ respectively.

\subsubsection{The Influence on Acoustic Comfort}

Figure $7 \mathrm{~d}$ shows the relationship between crowd density and acoustic comfort: when crowd density increased, the value of acoustic comfort decreased in Kuan Alley, while the value of acoustic comfort in Central Avenue took a parabolic shape that first increased and then decreased, with $R^{2}=0.448$ in Kuan Alley and 0.485 in Central Avenue $(p<0.001)$. The possible reasons are as follows. The first reason is the spatial perceptions of users in these two commercial pedestrian streets, which resulted in the different evaluations of acoustic comfort when crowd density was $0-0.2$ persons $/ \mathrm{m}^{2}$. The shop openness was semi-open in Kuan Alley, while the shops in Central Avenue were closed. When crowd density was lower, such as $0-0.2$ persons $/ \mathrm{m}^{2}$, the users in commercial pedestrian streets with semi-open state shops preferred quieter sound environments, and therefore, the acoustic comfort of users was higher. The users in Central Avenue would feel deserted when crowd density was $0-0.2$ persons $/ \mathrm{m}^{2}$, even if there was no significant difference in the sound pressure level in these two commercial pedestrian streets. Furthermore, the difference in acoustic comfort in these two commercial pedestrian streets resulted from cultural differences in Central Avenue and Kuan Alley. The voices of users in southern China were louder than the voices of users in Central Avenue when crowd density remained constant. When the number of talkers was equal, the level of sound pressure in Kuan Alley was higher than that in Central Avenue. Thus, the acoustic comfort in Kuan Alley decreased when crowd density increased because users in Kuan Alley liked a quiet environment. However, users in Central Avenue liked a busy environment, such as 0.1 to 0.3 persons $/ \mathrm{m}^{2}$, and they felt comfort from it.

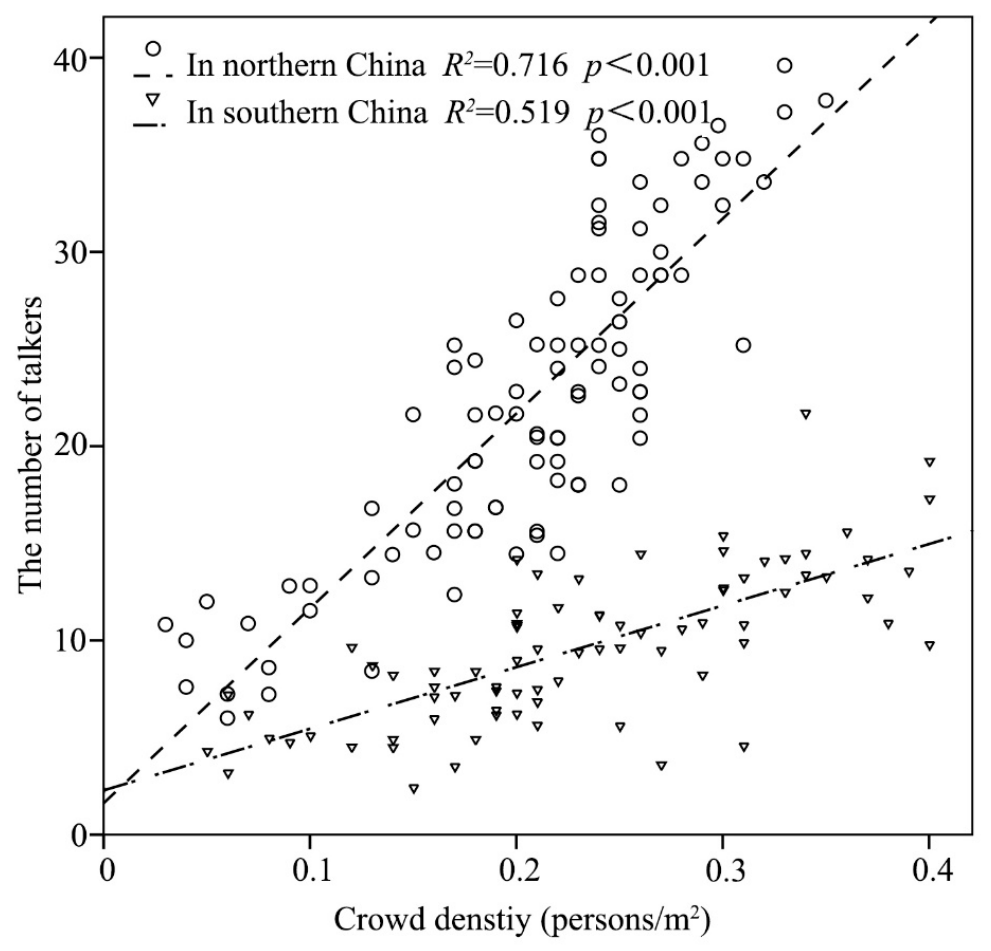

(a)

Figure 7. Cont. 


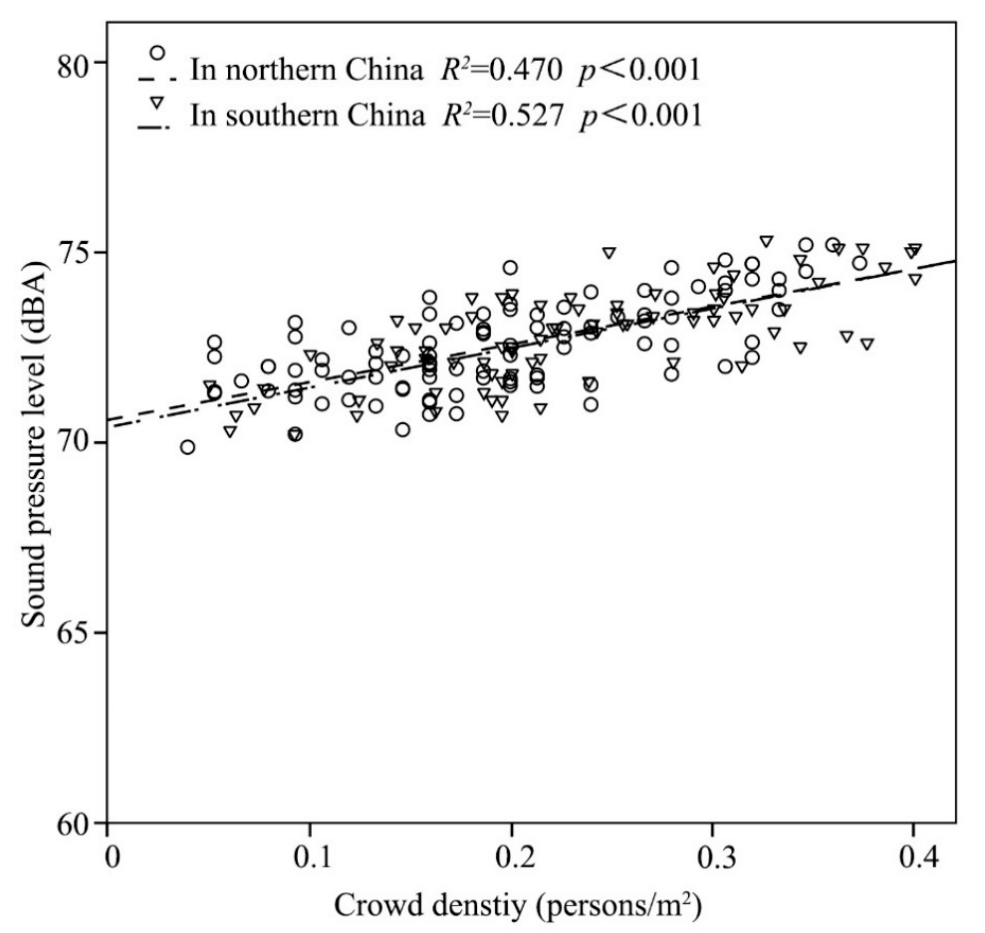

(b)

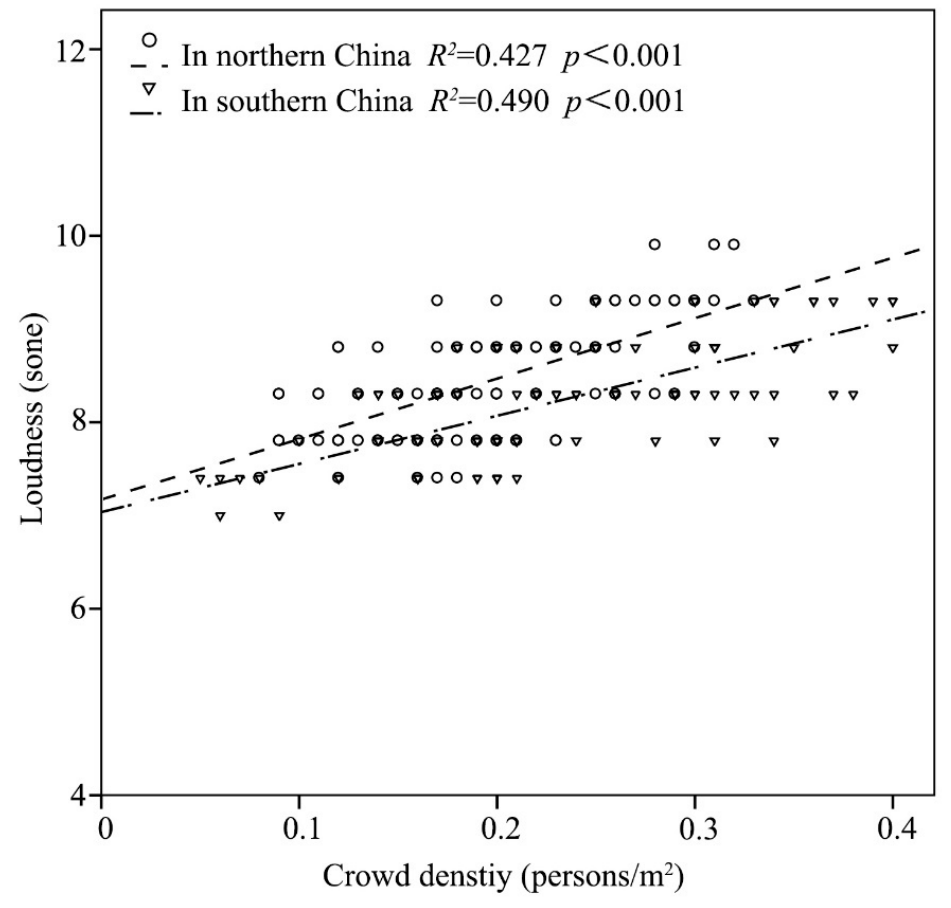

(c)

Figure 7. Cont. 


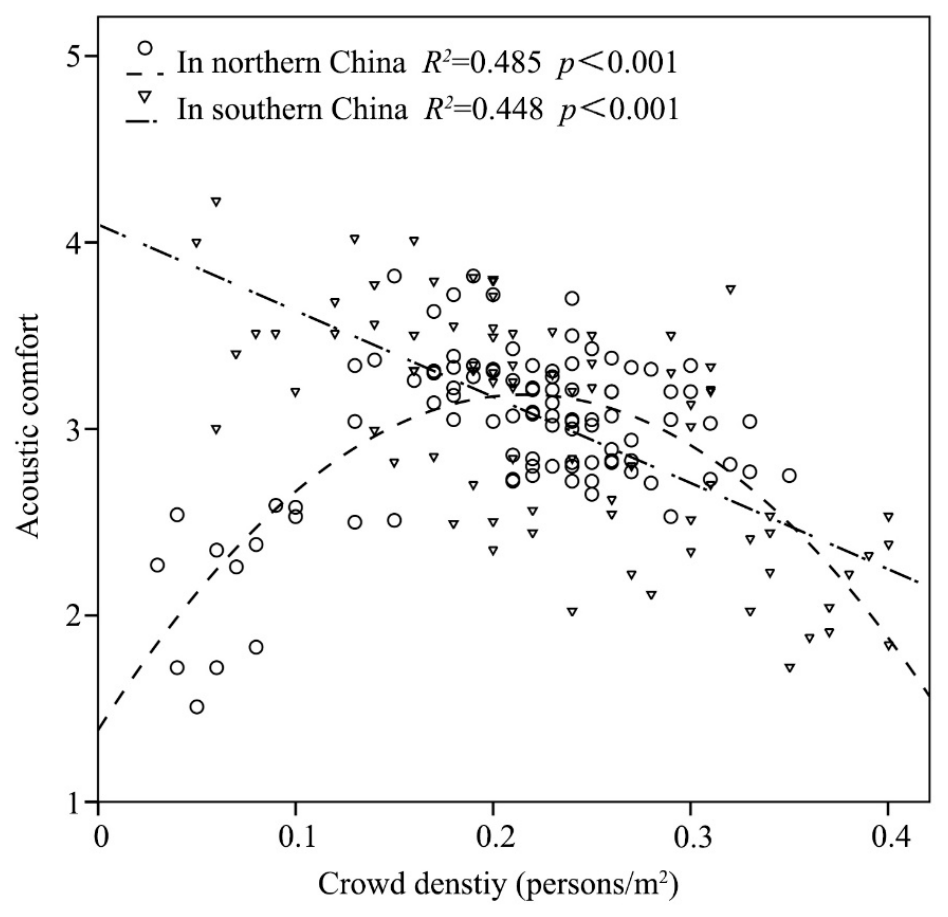

(d)

Figure 7. The influence of shop openness: (a) the relationship between crowd density and the number of talkers; (b) the relationship between crowd density and the level of sound pressure; (c) the relationship between crowd density and loudness; (d) the relationship between crowd density and acoustic comfort.

\subsection{The Influence of Season}

\subsubsection{The Influence on the Number of Talkers}

Figure 8a shows the relationship between crowd density and the number of talkers: when crowd density increased, the number of talkers also increased in both winter and summer, with $R^{2}=0.716$ in winter and 0.719 in summer $(p<0.001)$. The results showed that although the number of talkers in winter was slightly higher than the number of talkers in summer (with the same crowd density in each case), there was no statistically significant difference between the seasons and the number of talkers $(p>0.05)$.

\subsubsection{The Influence on Sound Environment}

Figure $8 \mathrm{~b}$ shows the relationship between crowd density and A-weight sound pressure level: when crowd density increased, the level of sound pressure also increased in both winter and summer, with $R^{2}=0.470$ in winter and 0.505 in summer $(p<0.001)$. The level of sound pressure was higher in winter than in summer, with an average difference of $1.6 \mathrm{dBA}$ when crowd density ranged from 0 to 0.3 persons $/ \mathrm{m}^{2}$. However, when crowd density ranged from 0.3 to 0.4 persons $/ \mathrm{m}^{2}$, the level of the sound pressure was lower in winter than in summer, with an average difference of $0.2 \mathrm{dBA}$. The effects of crowd density on the range of the sound pressure level in these two seasons were also significantly different. When the crowd density increased by 0.1 persons $/ \mathrm{m}^{2}$, the level of sound pressure in winter increased by $1.3 \mathrm{dBA}$ and $2.2 \mathrm{dBA}$ in summer. Considering that there was no statistically significant difference between seasons and the number of talkers, differences in the crowds' clothing may influence the sound environment in pedestrian streets, especially in winter.

Figure $8 c$ shows the relationship between crowd density and loudness. It is seen that when crowd density increases, loudness increases in both winter and summer, with $R^{2}=0.427$ in winter and 0.438 
in summer $(p<0.001)$. The loudness is higher in winter than in summer, with a difference of 0.87 sone, with a crowd density range from 0 to 0.4 persons $/ \mathrm{m}^{2}$.

\subsubsection{The Influence on Acoustic Comfort}

Figure 8d shows the relationship between crowd density and acoustic comfort: when crowd density increased, the value of acoustic comfort took a parabolic shape that first increased and then decreased in both winter and summer, with $R^{2}=0.485$ in winter and 0.434 in summer $(p<0.001)$. The results indicate that the range of crowd density in which the acoustic comfort was higher $(>3.0)$ was $0.15-0.3$ persons $/ \mathrm{m}^{2}$ in winter. When crowd density ranged from $0.15-0.3$ persons $/ \mathrm{m}^{2}$ in summer, acoustic comfort increased even an even higher value, with a value of 3.4 .

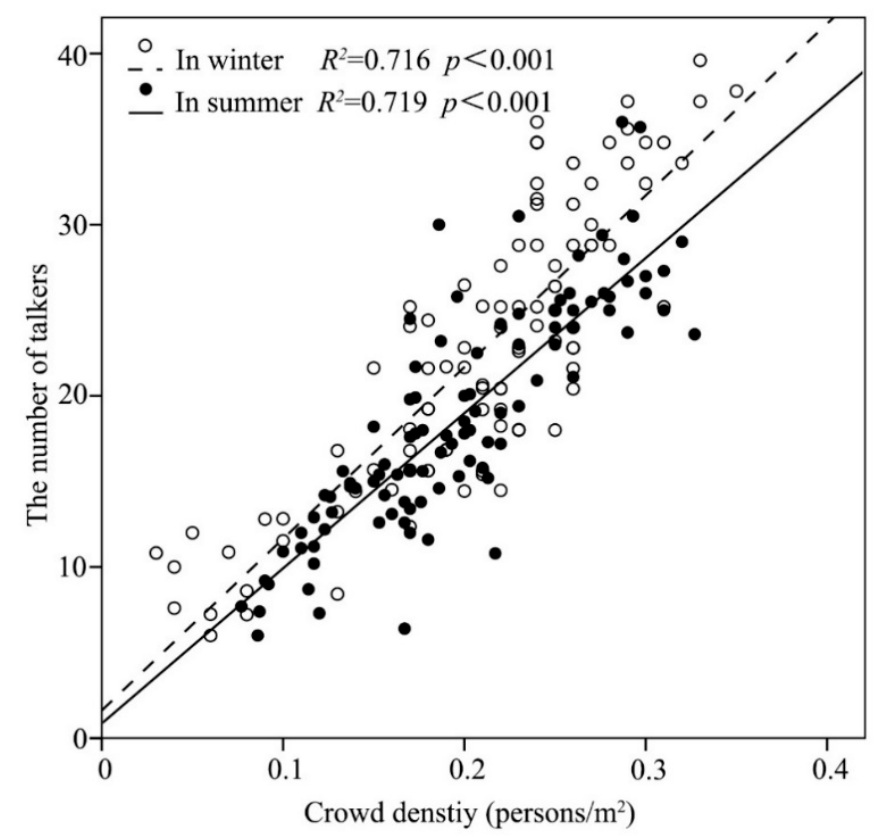

(a)

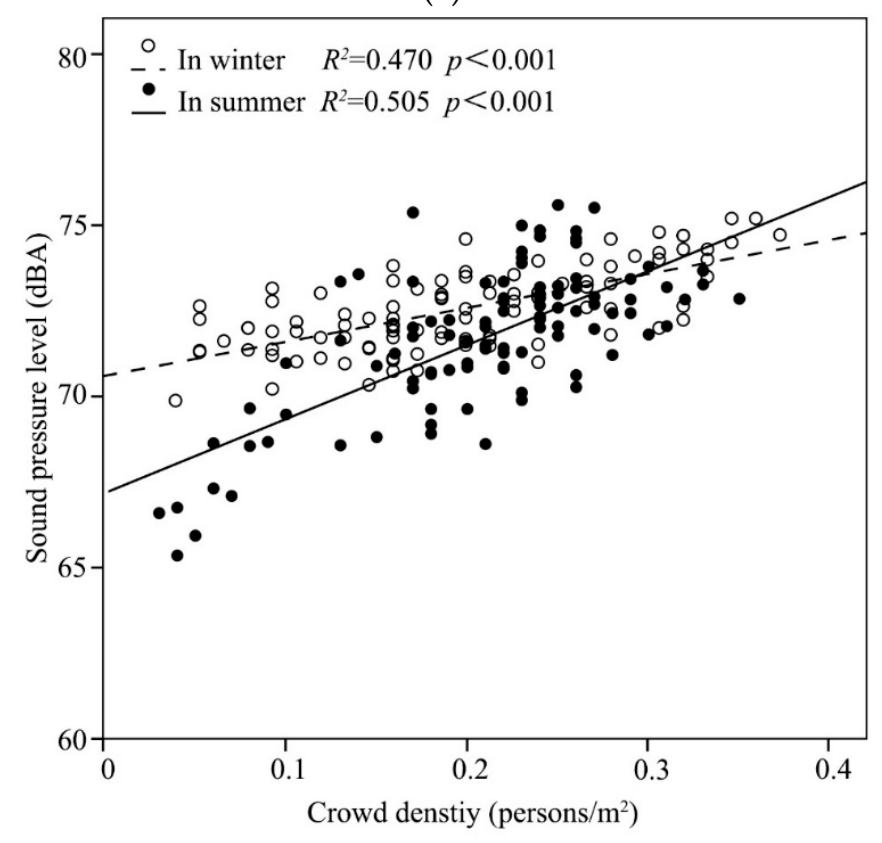

(b)

Figure 8. Cont. 


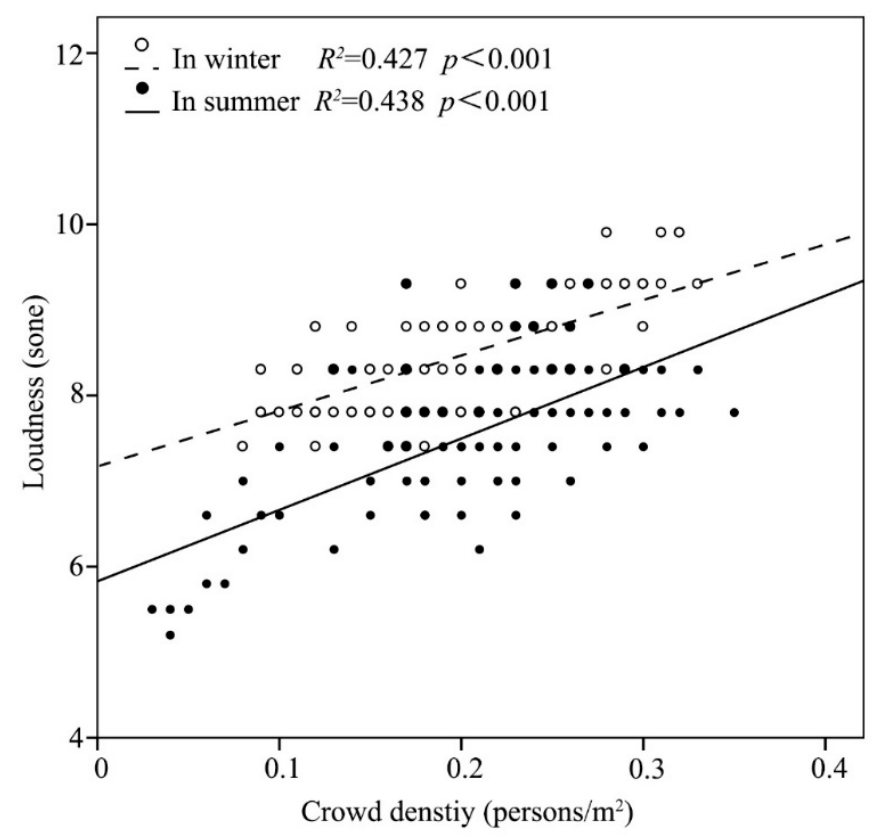

(c)

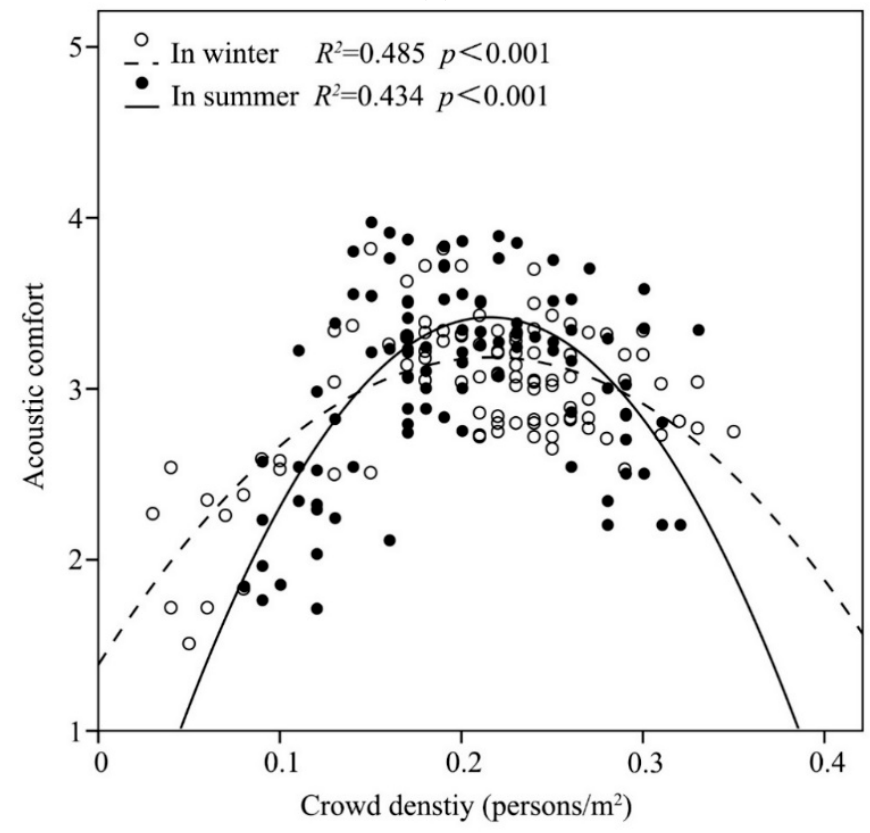

(d)

Figure 8. The influence of the season: (a) the relationship between crowd density and the number of talkers; (b) the relationship between crowd density and the level of sound pressure; (c) the relationship between crowd density and loudness; (d) the relationship between crowd density and acoustic comfort.

\subsection{The Influence of Commercial Function}

\subsubsection{The Influence on the Number of Talkers}

As Figure 9a shows, when the crowd density ranged from $0-0.4$ persons $/ \mathrm{m}^{2}$, the number of talkers increased when the crowd density increased, with different commercial functions. Meanwhile, the slopes of these three curves of regression were also similar. As the crowd density increased by 0.1 persons $/ \mathrm{m}^{2}$, the number of talkers increased by 3.4 persons in the Pe zone and was higher by 0.01 and 0.2 persons than that in the Di zone and Sp zone, respectively. Thus, the numbers of 
talkers, with different crowd densities in the three dominant sound source zones, are not significantly different $(p>0.1)$.

\subsubsection{The Influence on Sound Environment}

Figure $9 \mathrm{~b}$ shows the relationship between crowd density and A-weight sound pressure level: $R^{2}$ was 0.638 in the Di zone; 0.527 in the Sp zone; and 0.621 in the Pe zone $(p<0.001)$. In these three zones, the level of sound pressure takes a linear trend of continuous increase as the crowd density increases. The level of sound pressure indicates significantly different ranges when the crowd density ranges from 0 to 0.4 persons $/ \mathrm{m}^{2}$, with three commercial functions. In the Di zone, the sound pressure level ranged from 68 to $77 \mathrm{dBA}$, while the ranges were 70-75 dBA and 71-77 dBA in the Sp and the Pe zone, respectively. When the crowd density is constant, such as a crowd density of 0.1 persons $/ \mathrm{m}^{2}$, the sound pressure level in the Pe zone was higher than that in the Di zone ( $2.9 \mathrm{dBA})$ and Sp zone $(1.0 \mathrm{dBA})$. The sound pressure level in the Pe zone was higher than that in the Di zone (2.8 dBA) and the Sp zone $(1.7 \mathrm{dBA})$ when the crowd density was 0.3 persons $/ \mathrm{m}^{2}$. When the crowd density ranged from 0.1 to 0.3 persons $/ \mathrm{m}^{2}$, the level of sound pressure in the Di zone and Pe zone increased more quickly than that in the Sp zone. Considering that the number of talkers in the three zones was not significantly different $(p>0.1)$, the reason may be that the voices of persons in the Di zone and Pe zone increased when the crowd density increased. In the Di zone, when the crowd density increased, the sound pressure level of speech increased, and the sound of hawking was masked by speech and other sounds. To attract more customers, the volume of the hawking produced by sellers may be enhanced. In the Pe zone, instrumental music was unusual in commercial pedestrian streets, which may arouse users' curiosity, and the conversation produced by users may increase. However, in the Sp zone, background music was common in commercial pedestrian streets so users pay little attention to background music.

Figure 9c shows the relationship between crowd density and loudness, where it is seen that $R^{2}$ is 0.644 in the Di zone, 0.490 in the Sp zone, and 0.621 in the Pe zone $(p<0.001)$. In these three zones, the loudness has a linear trend of continuous increase as the crowd density increases. The loudness in the Pe zone is considerably higher than that in the Di zone (1.83 sone) and the Sp zone (1.12 sone), when the crowd density ranges from 0 to 0.4 persons $/ \mathrm{m}^{2}$.

\subsubsection{The Influence on Acoustic Comfort}

Figure $9 \mathrm{~d}$ shows the relationship between crowd density and acoustic comfort: when crowd density increased, the value of acoustic comfort decreased, with $R^{2}=0.418$ in the Di zone; 0.448 in the Sp zone; and 0.434 in the Pe zone $(p<0.001)$. Comparing the value of acoustic comfort in three zones, it was interesting to note that although the sound pressure level was highest in the Pe zone, the acoustic comfort was also highest in the Pe zone. This may indicate that a lower sound pressure level does not enhance the evaluation of users that may be influenced by dominant sound sources that can attract users. Acoustic comfort in the Pe zone was higher than that in the Di zone (0.2-0.4) and Sp zone $(0.3-0.4)$, when the crowd density was $0.1-0.3$ persons $/ \mathrm{m}^{2}$. When the crowd density ranged from 0 to 0.2 persons $/ \mathrm{m}^{2}$, the acoustic comfort in the Sp zone was higher than that in the Di zone. However, the acoustic comfort in the Sp zone was lower than that in the Di zone when the crowd density ranged from 0.2 to 0.4 persons $/ \mathrm{m}^{2}$. 


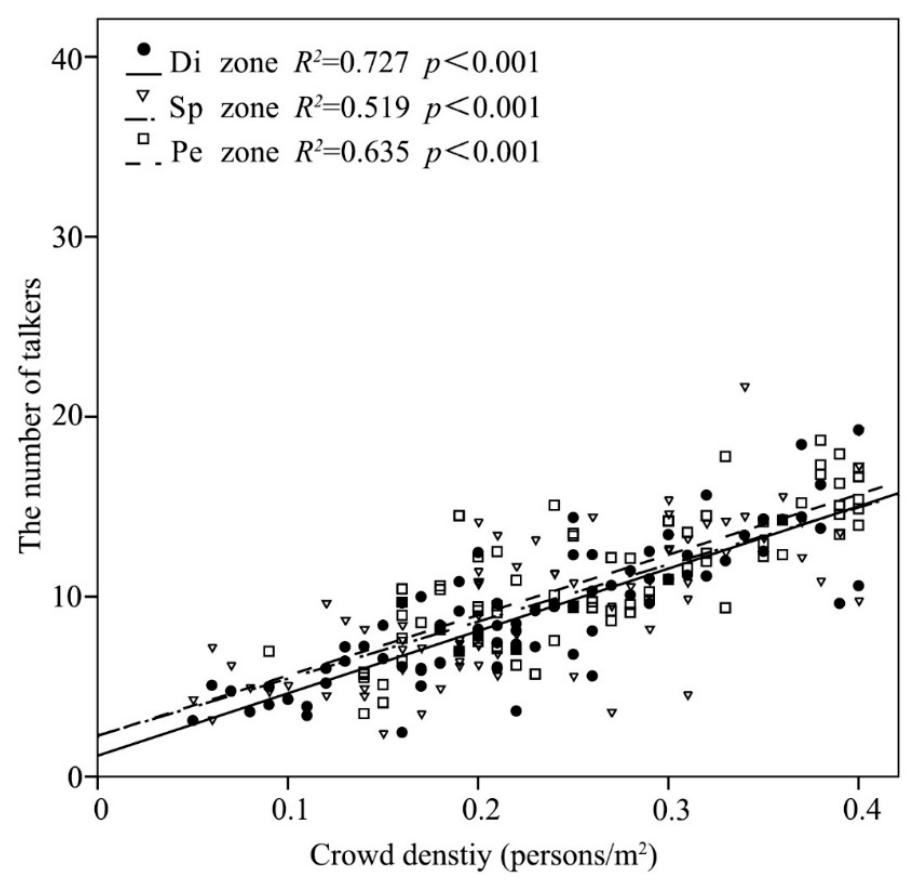

(a)

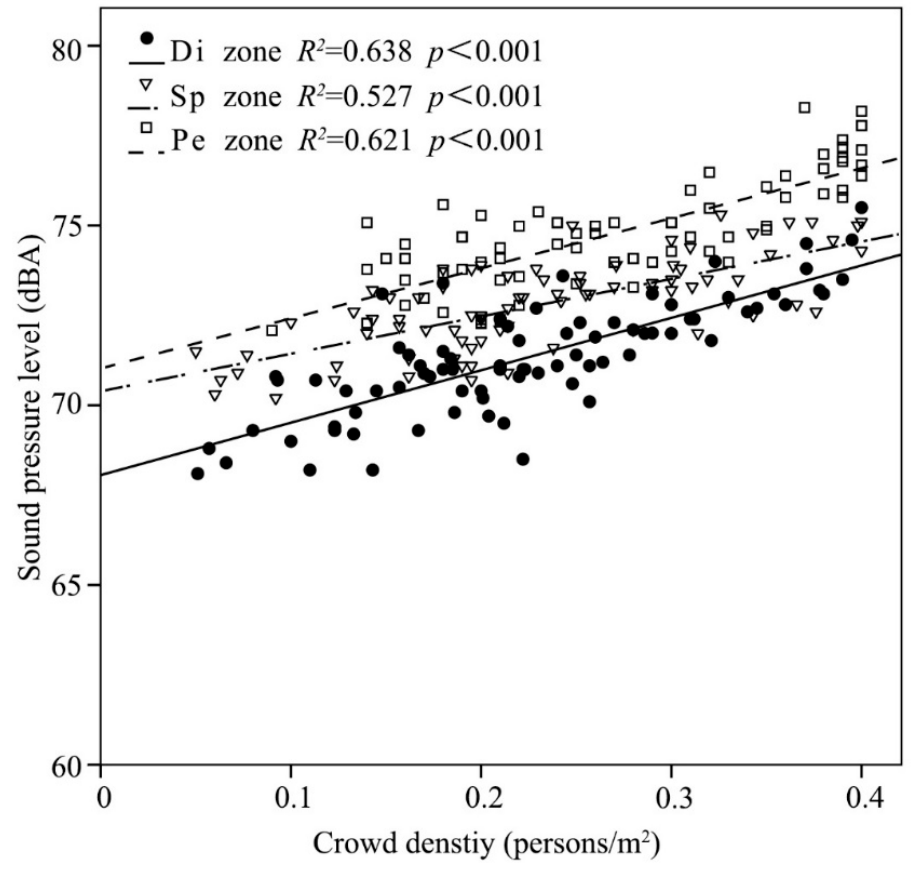

(b)

Figure 9. Cont. 


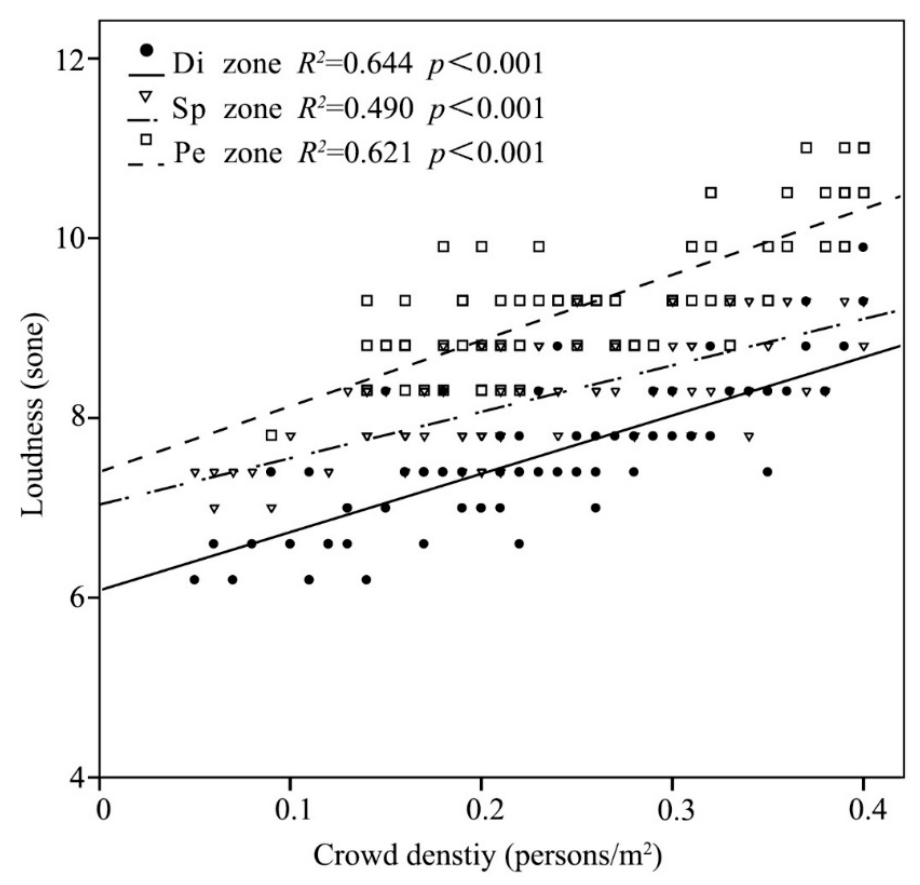

(c)

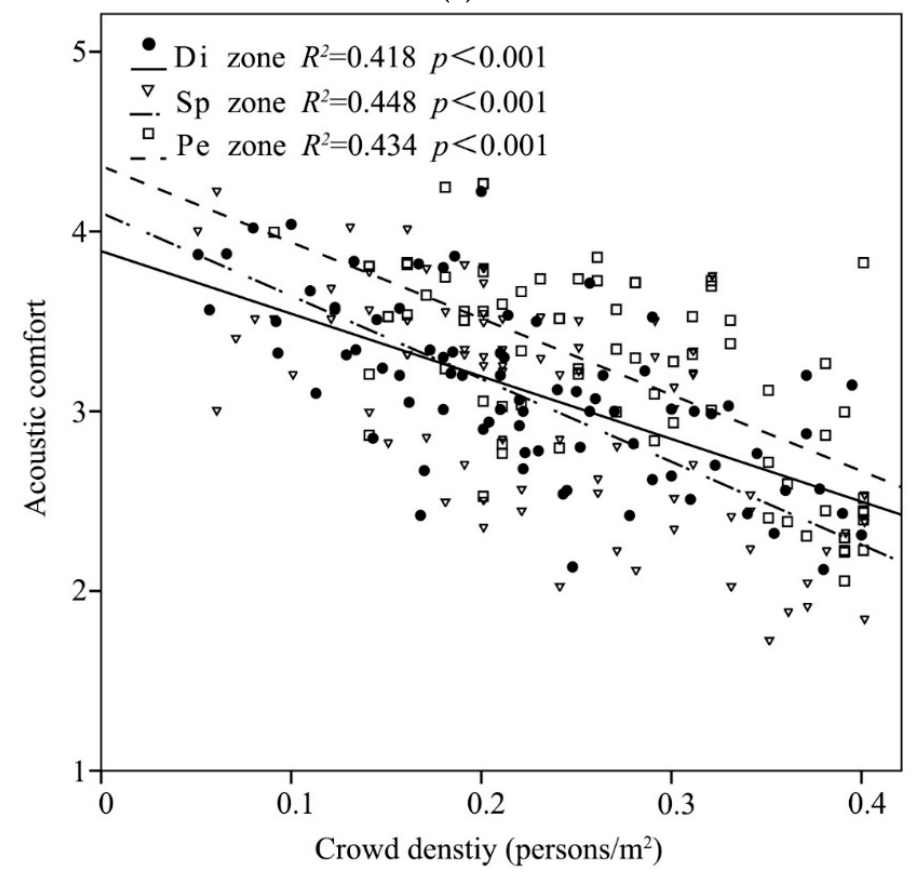

(d)

Figure 9. The influence of commercial function: (a) the relationship between crowd density and the number of talkers; (b) the relationship between crowd density and sound pressure level; (c) the relationship between crowd density and loudness; (d) the relationship between crowd density and acoustic comfort.

\section{Discussion}

It has been demonstrated that the level of sound pressure can increase as the crowd density increases. However, evidence of how the crowd density changes the sound field and whether the conversation behavior of users can influence the sound field has not been found in previous studies $[27,64]$. In fact, the number of talkers will also increase when crowd density increases. However, the issue of whether the number of talkers can affect the sound pressure level has not been determined 
prior to this study. Thus, in this section, we discuss some statistical methods that were used to determine the effect.

First, a Pearson's correlation analysis was used to calculate the relationship between the number of talkers and the level of the sound pressure, and a two-tail $t$-test was used to test the significance of the difference. As Table 5 shows, the results demonstrated a positive association between the number of talkers and the sound pressure level $(p<0.001)$. As the number of talkers increases, the level of sound pressure also increases. Secondly, we also attempted to use a linear regression to explain the relationship between the number of talkers and sound pressure level. The value of $R^{2}$ in the regressions ranged from $0.292-0.520(p<0.001)$, which meant that some models were not fit to explain the relationship between the variables accurately [71,72]. Thus, a crosstab analysis was used to explain the correlation extent and a chi-square test was used to test the significance of the difference. Cross-tabulation presents a table in matrix form that displays the frequency distribution of the variables. A crosstab was used to examine the correlations between survey data based on cross-tabulation [73]. In Table 6 , as the number of talkers increased, the data in the range of 68-70 dBA and 70-72 dBA followed a decreasing trend, while the data in the range of 72-74 dBA and 74-76 dBA followed an increasing trend $(p<0.001)$. When the number of talkers increased from $0-10$ persons to $10-20$ persons, the data decreased by $16.0 \%$ in the range of $68-70 \mathrm{dBA}$ and $70-72 \mathrm{dBA}$, and increased $16.0 \%$ in the range of 72-74 dBA and 74-76 dBA. When the number of talkers reached 30-40 persons, the level of the sound pressure did not increase because $72.0 \%$ of data focused on the range of $72-74 \mathrm{dBA}$, and only $20.0 \%$ of the data reached the range of 74-76 dBA.

In order to analyze the influence factors of acoustic comfort, a multiple logistic regression analysis was used to establish the relationship among acoustic comfort and other factors, including shop openness, season, commercial function, crowd density, sound pressure level, and the number of talkers, as shown in Table 7. The results indicated that some factors, such as shop openness, commercial function, and crowd density, were significantly correlated with acoustic comfort $(p<0.001)$, while there was no significant influence on the acoustic comfort from the season, number of talkers, sound pressure level, and loudness $(p>0.1)$.

Table 5. The relationship between the number of talkers and the sound pressure level.

\begin{tabular}{|c|c|c|c|c|c|}
\hline \multirow{3}{*}{$\begin{array}{c}\text { Commercial Pedestrian Street } \\
\text { Commercial Function } \\
\text { Survey Season } \\
\end{array}$} & \multicolumn{3}{|c|}{ Kuan Alley } & \multirow{2}{*}{\multicolumn{2}{|c|}{$\begin{array}{c}\text { Central Avenue } \\
\mathrm{Sp}\end{array}$}} \\
\hline & \multirow[t]{2}{*}{ Di } & \multirow{2}{*}{$\frac{\mathrm{Sp}}{\text { Winter }}$} & \multirow[t]{2}{*}{$\mathrm{Pe}$} & & \\
\hline & & & & Summer & Winter \\
\hline$R /$ & 0.721 & 0.541 & 0.680 & 0.670 & 0.606 \\
\hline Sig & $0.000^{* *}$ & $0.000^{* *}$ & $0.000^{* *}$ & $0.000^{* *}$ & $0.000^{* *}$ \\
\hline
\end{tabular}

Table 6. The cross-tabulation of the number of talkers and sound pressure level.

\begin{tabular}{ccccccc}
\hline \multirow{2}{*}{ The Number of Talkers } & \multicolumn{5}{c}{ Sound Pressure Level } \\
\cline { 2 - 7 } & & $\mathbf{6 8 - 7 0 ~ d B A}$ & $\mathbf{7 0 - 7 2} \mathbf{~ d B A}$ & $\mathbf{7 2 - 7 4} \mathbf{d B A}$ & $\mathbf{7 4 - 7 6 ~ d B A}$ & Total \\
\hline \multirow{2}{*}{$0-10$ persons } & $\mathrm{a}$ & 25 & 65 & 66 & 24 & 180 \\
& $\mathrm{~b}$ & $13.9 \%$ & $36.1 \%$ & $36.7 \%$ & $13.3 \%$ & $100.0 \%$ \\
\hline \multirow{2}{*}{$10-20$ persons } & $\mathrm{a}$ & 7 & 59 & 83 & 45 & 194 \\
& $\mathrm{~b}$ & $3.6 \%$ & $30.4 \%$ & $42.8 \%$ & $23.2 \%$ & $100.0 \%$ \\
\hline \multirow{2}{*}{$20-30$ persons } & $\mathrm{a}$ & 3 & 19 & 35 & 19 & 76 \\
& $\mathrm{~b}$ & $3.9 \%$ & $25.0 \%$ & $46.1 \%$ & $25.0 \%$ & $100.0 \%$ \\
\hline \multirow{2}{*}{$30-40$ persons } & $\mathrm{a}$ & 0 & 2 & 18 & 5 & 25 \\
& $\mathrm{~b}$ & $0 \%$ & $8.0 \%$ & $72.0 \%$ & $20.0 \%$ & $100.0 \%$ \\
\hline \multirow{2}{*}{ Total } & $\mathrm{a}$ & 35 & 145 & 202 & 93 & 475 \\
& $\mathrm{~b}$ & $7.4 \%$ & $30.5 \%$ & $42.5 \%$ & $19.6 \%$ & $100.0 \%$ \\
\hline
\end{tabular}

$\mathrm{a}$ and $\mathrm{b}$ refer to the count and percentage of the number of talkers within the sound pressure level. 
Table 7. The relationship between acoustic comfort and influence factors.

\begin{tabular}{ccccc}
\hline Influence Factors & Model Fitting Criteria & Chi-Square & df & Sig \\
\hline Shop openness & 301.857 & 12.103 & 3 & $0.007^{* *}$ \\
season & 291.479 & 1.725 & 3 & 0.631 \\
Commercial function & 321.074 & 31.320 & 6 & $0.000^{* *}$ \\
Crowd density & 384.414 & 94.659 & 9 & $0.000^{* *}$ \\
The number of talkers & 307.046 & 17.291 & 12 & 0.139 \\
Sound pressure level & 300.004 & 10.249 & 12 & 0.594 \\
Loudness & 293.694 & 3.939 & 9 & 0.915 \\
\hline \multicolumn{5}{c}{ means $p<0.01}$.
\end{tabular}

\section{Conclusions}

Based on crowd measurements and a questionnaire survey of two commercial pedestrian streets, this study examined the different influences of contextual factors on soundscape considering the shop openness, season and commercial function. The following conclusions can be drawn from the results:

First, regarding the influence of shop openness, the number of talkers in Central Avenue was greater than the number of talkers in Kuan Alley when the crowd density remained constant. The average deviation of the number of talkers between Kuan Alley and Central Avenue was 13.0 persons. Nevertheless, it was interesting to note that there was no significant difference in the sound pressure level in these two commercial pedestrian streets. When crowd density increased, acoustic comfort trended downward in Kuan Alley, while the value of acoustic comfort in Central Avenue took a parabolic shape that first increased and then decreased.

Second, in terms of the influence of season, there is also no significant difference between the number of talkers in summer and the number of talkers in winter. However, when the crowd density increased by 0.1 persons $/ \mathrm{m}^{2}$, the level of the sound pressure increased by $1.3 \mathrm{dBA}$ in winter and $2.2 \mathrm{dBA}$ in summer. When the crowd density increased, the value of acoustic comfort took a parabolic shape that first increased and then decreased in both winter and summer.

Third, regarding the influence of the commercial function, as the crowd density increased by 0.1 persons $/ \mathrm{m}^{2}$, the number of talkers increased by 3.4 persons in the Pe zone, 3.4 persons in the Di zone and 3.6 persons in the Sp zone, respectively. The sound pressure level in the Pe zone was higher than that in the Di zone $(2.9 \mathrm{dBA})$ and $\mathrm{Sp}$ zone $(1.0 \mathrm{dBA})$ with a crowd density of 0.1 persons $/ \mathrm{m}^{2}$ even when the numbers of talkers in the three zones were not significantly different. Additionally, acoustic comfort in the Pe zone was highest among these three zones and the value was 3.3, which was not consistent with our expectations.

In addition, the relationship between the number of talkers and the sound pressure level was also discussed in this paper. It also presented a positive trend where, as the number of talkers increased, the frequency of the recordings in the low range (68-72 dBA) decreased, while the times of recordings in the high range (72-76 dBA) increased.

Being that this study is carried out only in commercial pedestrian streets of typical cities in China, commercial pedestrian streets in other regions of China were not analyzed in this study. Moreover, the findings in this study were limited to northern and southern China; the effects of contextual factors on the soundscape in eastern China and western China may also be different. Furthermore, the difference in the conversation frequency and duration of users between southern China and northern China may influence the soundscape experience in urban open spaces. Thus, these issues should be further examined in future studies. Finally, the results in this study is also of relevance for indoor soundscaping, especially long spaces $[74,75]$.

Author Contributions: Conceptualization, S.Z., X.Z., Q.M. and J.K.; Methodology, S.Z., X.Z., Q.M. and J.K.; Investigation, S.Z.; Formal Analysis, S.Z.; Data Curation, S.Z.; Writing-Original Draft Preparation, S.Z.; Writing-Review \& Editing, S.Z., X.Z., Q.M. and J.K.; Visualization, S.Z.; Supervision, X.Z., Q.M. and J.K.; Project Administration, X.Z., and Q.M.; Funding Acquisition, X.Z., and Q.M. 
Funding: This research was funded by the National Natural Science Foundation of China (grant numbers 51678180, 51878210, 51438005, 51878206, 51778169).

Acknowledgments: The authors wish to thank the Building Street Management Department in Harbin and Chengdu city in China for their permission for soundscape investigation in Central Avenue and Kuan Alley, respectively.

Conflicts of Interest: The authors declare no conflict of interest.

\section{References}

1. Rehan, R.M. The phonic identity of the city urban soundscape for sustainable spaces. HBRC J. 2016, 12, 337-349. [CrossRef]

2. Rey, G.G.; Barrigón, J.M.; Montes, D.G.; Atanasio, P.M. Relationships among satisfaction, noise perception, and use of urban green spaces. Sci. Total Environ. 2018, 624, 438-450.

3. Zhang, X.; Ba, M.; Kang, J.; Meng, Q. Effect of soundscape dimensions on acoustic comfort in urban open public spaces. Appl. Acoust. 2018, 133, 73-81. [CrossRef]

4. Barclay, M.; Kang, J.; Sharples, S. Combining noise mapping and ventilation performance for non-domestic buildings in an urban area. Build. Environ. 2012, 52, 68-76. [CrossRef]

5. Defrance, J.; Jean, P. Integration of the efficiency of noise barrier caps in a 3D ray tracing method. Case of a T-shaped diffracting device. Appl. Acoust. 2003, 64, 765-780. [CrossRef]

6. Bastiánmonarca, N.A.; Suárez, E.; Arenas, J.P. Assessment of methods for simplified traffic noise mapping of small cities: Casework of the city of Valdivia, Chile. Sci. Total Environ. 2016, 550, 439-448. [CrossRef] [PubMed]

7. Aguilera, I.; Foraster, M.; Basagaña, X.; Corradi, E.; Deltell, A.; Morelli, X.; Phuleria, H.C.; Ragettli, M.S.; Rivera, M.; Thomasson, A.; et al. Application of land use regression modelling to assess the spatial distribution of road traffic noise in three European cities. J. Expo. Sci. Environ. Epidemiol. 2014, $25,97$. [CrossRef] [PubMed]

8. Fecht, D.; Hansell, A.L.; Morley, D.; Dajnak, D.; Vienneau, D.; Beevers, S.; Toledano, M.B.; Kelly, F.J.; Anderson, H.R.; Gulliver, J. Spatial and temporal associations of road traffic noise and air pollution in London: Implications for epidemiological studies. Environ. Int. 2016, 88, 235-242. [CrossRef] [PubMed]

9. Adler, A.C.; Nathanson, B.H.; Raghunathan, K.; Mcgee, W.T. Effects of body surface area-indexed calculations in the morbidly obese: A mathematical analysis. J. Cardiothorac. Vasc. Anesth. 2013, 27, 1140-1144. [CrossRef]

10. Hong, J.Y.; Jin, Y.J. Relationship between spatiotemporal variability of soundscape and urban morphology in a multifunctional urban area: A case study in Seoul, Korea. Build. Environ. 2017, 126, 382-395. [CrossRef]

11. Meng, Q.; Kang, J. Effect of sound-related activities on human behaviours and acoustic comfort in urban open spaces. Sci. Total Environ. 2016, 573, 481-493. [CrossRef] [PubMed]

12. Liu, J.; Kang, J.; Behm, H.; Luo, T. Effects of landscape on soundscape perception: Soundwalks in city parks. Landsc. Urban Plan. 2014, 123, 30-40. [CrossRef]

13. Kang, J. Noise management: Soundscape approach. In Encyclopedia of Environmental Health; Elsevier: Amsterdam, The Netherlands, 2011; pp. 174-184.

14. Jin, Y.J.; Lee, P.J.; You, J.; Kang, J. Acoustical characteristics of water sounds for soundscape enhancement in urban open spaces. J. Acoust. Soc. Am. 2012, 131, 2101-2109. [CrossRef] [PubMed]

15. Buratti, C.; Belloni, E.; Merli, F.; Ricciardi, P. A new index combining thermal, acoustic, and visual comfort of moderate environments in temperate climates. Build. Environ. 2018, 139, 27-37. [CrossRef]

16. Chen, Z.; Li, Z.; Wang, S.; Yin, F. A microphone position calibration method based on combination of acoustic energy decay model and TDOA for distributed microphone array. Appl. Acoust. 2015, 95, 13-19. [CrossRef]

17. Yu, L.; Kang, J. Factors influencing the sound preference in urban open spaces. Appl. Acoust. 2010, 71, 622-633. [CrossRef]

18. Kang, J. Urban sound environment. Build. Acoust. 2013, 14, 159-160. [CrossRef]

19. Liu, F.; Kang, J. A grounded theory approach to the subjective understanding of urban soundscape in Sheffield. Cities 2016, 50, 28-39. [CrossRef]

20. Zhang, M.; Kang, J. A cross-cultural semantic differential analysis of the soundscape in urban open public spaces. Tech. Acoust. 2006, 25, 523-532. 
21. Salomons, E.M.; Pont, M.B. Urban traffic noise and the relation to urban density, form, and traffic elasticity. Landsc. Urban Plan. 2012, 108, 2-16. [CrossRef]

22. Meng, Q.; Kang, J. The influence of crowd density on the sound environment of commercial pedestrian streets. Sci. Total Environ. 2015, 511, 249-258. [CrossRef] [PubMed]

23. Lai, F.O.; Ghosh, S. Urban cities and road traffic noise: Reduction through vegetation. Appl. Acoust. 2017, $120,15-20$.

24. Kang, J. Numerical modeling of the sound fields in urban squares. J. Acoust. Soc. Am. 2005, 117, $3695-3706$. [CrossRef] [PubMed]

25. Pérez-Martínez, G.; Martinez, A.J.; Ruiz, D.P. Soundscape assessment of a monumental place: A methodology based on the perception of dominant sounds. Landsc. Urban Plan. 2018, 169, 12-21. [CrossRef]

26. Yang, H.S.; Kang, J.; Kim, M.J. An experimental study on the acoustic characteristics of outdoor spaces surrounded by multi-residential buildings. Appl. Acoust. 2017, 127, 147-159. [CrossRef]

27. Meng, Q.; Zhang, S.; Kang, J. Effects of typical dining styles on conversation behaviours and acoustic perception in restaurants in China. Build. Environ. 2017, 121, 148-157. [CrossRef]

28. Meng, Q.; Sun, Y.; Kang, J. Effect of temporary open-air markets on the sound environment and acoustic perception based on the crowd density characteristics. Sci. Total Environ. 2017, 601-602, 1488-1495. [CrossRef]

29. Hong, J.Y.; Jin, Y.J. Influence of urban contexts on soundscape perceptions: A structural equation modeling approach. Landsc. Urban Plan. 2015, 141, 78-87. [CrossRef]

30. Song, X.; Lv, X.; Yu, D.; Wu, Q. Spatial-temporal change analysis of plant soundscapes and their design methods. Urban For. Urban Gree. 2018, 29, 96-105. [CrossRef]

31. Djekic, J.; Djukic, A.; Vukmirovic, M.; Djekic, P.; Brankovic, M.D. Thermal comfort of pedestrian spaces and the influence of pavement materials on warming up during summer. Energ Build. 2018, 159, 474-485. [CrossRef]

32. Tan, Z.; Roberts, A.C.; Christopoulos, G.I.; Kwok, K.W.; Car, J.; Li, X.; Soh, C.K. Working in underground spaces: Architectural parameters, perceptions and thermal comfort measurements. Tunn. Undergr. Space Technol. 2018, 71, 428-439. [CrossRef]

33. Tsitoura, M.; Tsoutsos, T.; Daras, T. Evaluation of comfort conditions in urban open spaces. Application in the island of Crete. Energy Convers. Manag. 2014, 86, 250-258. [CrossRef]

34. Qaoud, R.; Djamal, A. The impact of constructivism density of the urban tissue in improving the physical urban ambience of the free space-The street-for Saharian cities. The study of the case city of Biskra. Energy Procedia 2017, 119, 201-213. [CrossRef]

35. Han, X.; Huang, X.; Liang, H.; Ma, S.; Gong, J. Analysis of the relationships between environmental noise and urban morphology. Environ. Pollut. 2018, 233, 755-763. [CrossRef] [PubMed]

36. Liu, J.; Kang, J.; Luo, T.; Behm, H.; Coppack, T. Spatiotemporal variability of soundscapes in a multiple functional urban area. Landsc. Urban Plan. 2013, 115, 1-9. [CrossRef]

37. Shi, J.; Cui, L.; Ma, Y.; Du, H.; Wen, K. Trends in temperature extremes and their association with circulation patterns in China during 1961-2015. Atmos. Res. 2018, 212, 259-272. [CrossRef]

38. Kisenwether, J.S.; Sataloff, R.T. The Effect of Microphone Type on Acoustical Measures of Synthesized Vowels. J. Voice Off. J. Voice Found. 2015, 29, 548-551. [CrossRef]

39. Wiens, S.; Szychowska, M.; Eklund, R.; Nilsson, M.E. Data on the auditory duration mismatch negativity for different sound pressure levels and visual perceptual loads. Data in Brief 2017, 11, 159-164. [CrossRef]

40. Kang, J.; Meng, Q.; Jin, H. Effects of individual sound sources on the subjective loudness and acoustic comfort in underground shopping streets. Sci. Total Environ. 2012, 435-436, 80-89. [CrossRef]

41. Turchet, L.; Serafin, S. Investigating the amplitude of interactive footstep sounds and soundscape reproduction. Appl. Acoust. 2013, 74, 566-574. [CrossRef]

42. Goel, N.; Etwaroo, G.R. Bright light, negative air ions and auditory stimuli produce rapid mood changes in a student population: A placebo-controlled study. Psychol. Med. 2006, 36, 1253-1263. [CrossRef] [PubMed]

43. Yogameena, B.; Nagananthini, C. Computer vision based crowd disaster avoidance system: A survey. Int. J. Disast. Risk Reduct. 2017, 22, 95-129. [CrossRef]

44. Chan, A.B.; Liang, Z.S.J.; Vasconcelos, N. Privacy preserving crowd monitoring: Counting people without people models or tracking. In Proceedings of the IEEE Conference on Computer Vision and Pattern Recognition, Anchorage, AK, USA, 24-26 June 2008; pp. 1-7. 
45. Oakes, S.; North, A.C. Using music to influence cognitive and affective responses in queues of low and high crowd density. J. Mark. Manag. 2008, 24, 589-602. [CrossRef]

46. Primeau, K.E.; Witt, D.E. Soundscapes in the past: Investigating sound at the landscape level. J. Archaeol. Sci. Rep. 2017, 19, 875-885. [CrossRef]

47. Huffman, A.H.; Werff, B.R.V.D.; Henning, J.B.; Watrous-Rodriguez, K. When do recycling attitudes predict recycling? An investigation of self-reported versus observed behavior. J. Environ. Psychol. 2014, 38, 262-270. [CrossRef]

48. Haataja, E.; Malmberg, J.; Järvelä, S. Monitoring in collaborative learning: Co-occurrence of observed behavior and physiological synchrony explored. Comput. Hum. Behav. 2018, 87, 337-347. [CrossRef]

49. Greendemers, I.; Pelletier, L.G.; Ménard, S. The impact of behavioural difficulty on the saliency of the association between self-determined motivation and environmental behaviours. Can. J. Behav. Sci. 1997, 29, 157-166. [CrossRef]

50. Paulhus, D.L.; Vazire, S. The self-report method. In Handbook of Research Methods in Personality Psychology; Guilford Press: New York, NY, USA, 2009; pp. 224-239.

51. Vining, J.; Ebreo, A. Emerging theoretical and methodological perspectives on conservation behavior. Isr. J. Med. Sci. 2002, 3, 541-558.

52. Corral-Verdugo, V.C. Dual 'realities' of conservation behavior: Self-reports vs. observations of re-ues and recycling behavior. J. Environ. Psychol. 1997, 17, 135-145. [CrossRef]

53. Grint, N.J.; Beths, T.; Jean, Y.S.; Whay, H.R.; Murrell, J.C. Analysis of behaviors observed during mechanical nociceptive threshold testing in donkeys and horses. J. Equine Vet. Sci. 2017, 50, 102-109. [CrossRef]

54. Beechey, T.; Buchholz, J.; Keidser, G. Measuring communication difficulty through effortful speech production during conversation. Speech Commun. 2018, 100, 18-29. [CrossRef]

55. Duives, D.C.; Daamen, W.; Hoogendoorn, S.P. State-of-the-art crowd motion simulation models. Transp. Res. C Emerg. 2013, 37, 193-209. [CrossRef]

56. Haghani, M.; Sarvi, M. Crowd behaviour and motion: Empirical methods. Transp. Res. B Meth. 2018, 107, 253-294. [CrossRef]

57. Lu, L.; Chan, C.Y.; Wang, J.; Wang, W. A study of pedestrian group behaviors in crowd evacuation based on an extended floor field cellular automaton model. Transp. Res. C Emerg. 2016, 81, 317-329. [CrossRef]

58. Zhang, D.; Zhang, M.; Liu, D.; Kang, J. Soundscape evaluation in Han Chinese Buddhist temples. Appl. Acoust. 2016, 111, 188-197. [CrossRef]

59. Hong, J.Y.; Jin, Y.J. Exploring spatial relationships among soundscape variables in urban areas: A spatial statistical modelling approach. Landsc. Urban Plan. 2017, 157, 352-364. [CrossRef]

60. Zhang, E.; Zhang, Q.; Xiao, J.; Hou, L.; Guo, T. Acoustic comfort evaluation modeling and improvement test of a forklift based on rank score comparison and multiple linear regression. Appl. Acoust. 2018, 135, $29-36$. [CrossRef]

61. International Organization for Standardization (ISO). Acoustics-Soundscape-Part 2: Data Collection and Reporting Requirements; (ISO/TS 12913-2); ISO: Geneva, Switzerlan, 2018; pp. 1-29.

62. Liu, F.; Kang, J. Relationship between street scale and subjective assessment of audio-visual environment comfort based on 3D virtual reality and dual-channel acoustic tests. Build. Environ. 2018, 129, 35-45. [CrossRef]

63. Ren, X.; Kang, J. Effects of the visual landscape factors of an ecological waterscape on acoustic comfort. Appl. Acoust. 2015, 96, 171-179. [CrossRef]

64. Zhang, S.; Meng, Q.; Kang, J. The influence of crowd density on evaluation of soundscape in typical Chinese restaurant. In Proceedings of the INTER-NOISE 2016 - 45th International Congress and Exposition on Noise Control Engineering: Towards a Quieter Future, Hamburg, Germany, 21-24 August 2016; pp. 6150-6155.

65. Dubois, D.; Guastavino, C.; Raimbault, M. A cognitive approach to soundscapes : Using verbal data to access auditory categories. Acta Acust. United Acust. 2006, 92, 865-874.

66. Yu, L.; Kang, J. Modeling subjective evaluation of soundscape quality in urban open spaces: An artificial neural network approach. J. Acoust. Soc. Am. 2009, 126, 1163-1174. [CrossRef] [PubMed]

67. Kang, J. Urban Sound Environment; Taylor and Francis: London, UK, 2007.

68. Nordin, S.; Palmquist, E.; Claeson, A.S. The environmental symptom-attribution scale: Metric properties andnormative data. J. Environ. Psychol. 2013, 36, 9-17. [CrossRef]

69. Feeney, B.C. A Simple Guide to IBM SPSS Statistics for Version 20.0; Cengage Learning: Boston, MA, USA, 2012. 
70. Zhang, D.; Zhang, M.; Liu, D.; Kang, J. Sounds and sound preferences in Han Buddhist temples. Build. Environ. 2018, 142, 58-69. [CrossRef]

71. Azizi, A.; Ghaedrahmati, R. Optimizing and evaluating the operational factors affecting the cyanide leaching circuit of the Aghdareh gold processing plant using a CCD model. Proc. R. Soc. A Math. Phys. 2015, 471, 27-40. [CrossRef]

72. Ganic, E.; Dobrota, M.; Babic, O. Noise abatement measures at airports: Contributing factors and mutual dependence. Appl. Acoust. 2016, 112, 32-40. [CrossRef]

73. Tian, Y.; Liu, Y.; Liu, X.; Kong, X.; Liu, G. Restructuring rural settlements based on subjective well-being (SWB): A case study in Hubei province, central China. Land Use Policy 2017, 63, 255-265. [CrossRef]

74. Kang, J. A method for predicting acoustic indices in long enclosures. Appl. Acoust. 1997, 51, 169-180. [CrossRef]

75. Kang, J. The unsuitability of the classic room acoustical theory in long enclosures. Archit. Sci. Rev. 1996, 39, 89-94. [CrossRef]

(C) 2018 by the authors. Licensee MDPI, Basel, Switzerland. This article is an open access article distributed under the terms and conditions of the Creative Commons Attribution (CC BY) license (http://creativecommons.org/licenses/by/4.0/). 